مجلة جامعة أم درمان الاسلامية

https://iournal.oiu.edu.sd/index.php/oiui

2014; 10(2): 135-160

https://doi.org/ 10.52981/oiuj.v10i2.1660

ISSN: 5361-1858

\title{
اللغة أداة فكر واتصال
}

د ماجدة خلف الله العبيد"

المستخلص

اللغة كانت ومازالت أهمّ وسيلة اتصال نعبّر بها عن أفكارنا ومعارفنا وثقافتتا وحضارتتا ولمّا كانت المعرفة هى أساس الحضارة فإنّ اللغة هي وسيلتها في التعبير وكلّ المجتمعات استخدمت مختلف وسائل الاتصال لإبراز شكلها الحضاري من رسومات ونقوش ومخطوطات ولكن تظل اللغة هي أهمّها. لما كان الإعلام الوسيلة الأهم والأكثر

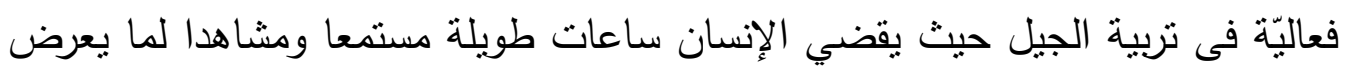

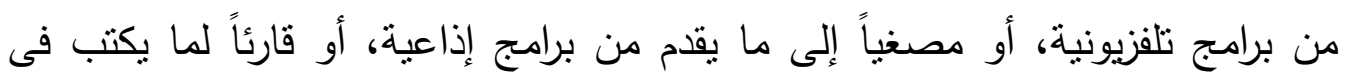
الصحف، بذلك أصبح الدور التوجيهي للإعلام أثندّ تأثيرا من الدور التوجيهي للمؤسسات التعليمية في بعض الأحيان، ممّا دفع الباحثين إلى القول " إن الإعلام هو المنهج التربوي الأول والمدرسة هي المنهج التربوي الثاني" وإذا كان للإعلام هذا الأثر الكبير في الحياة اللغوية والثقافية وإن اللغة كما هو معروف تكتسب بالسماع والمحاكاة فإن أجهزة الإعلام المسموعة والمرئية حين تلتزم باللغة العربية السليمة هي أحسن مصدر لتعليم اللغة والارتقاء بها وتطويرها، وفي الوقت ذاته يمكن أن تكون عنصرا من عناصر تأخر اللغة، ونسبة لأهمية اللغة وللأدوار المهمة التي تلعبها فى حياتنا على المستوبين العاطفي ولفي والوظيفي جاءت هذه الدراسة بعنوان (اللغة أداة فكر واتصال) واستخدمت الباحثة المنهج الوصفي التحليلي (الوثائقي) كمنهج كلى؛ وهو الذي يعتمد على تجميع الحقائق والمعلومات ثم مقارنتها وتحليلها وتفسيرها للوصول إلى تعميمات مقبولة. واشتملت الدراسة على ثلاتثة مباحث، وخلصت الدراسة إلى بعض النتائج والتوصيات. ” أستاذ مساعد بكلية المعلومات والإعلام والعلوم الإنسانية - جامعة عجمان للعلوم والتكنولوجيا 


\begin{abstract}
Human language has always been the most important means of communication used to transmit people's thoughts, knowledge, culture and civilization. Since knowledge is the basis of civilization, language has derived its importance from being its tool of expression. All societies have used different types of communication tools to highlight their forms of civilizationwhether drawings, engravings, or manuscripts- but language remains the most important of all forms of communication.

Since the media represents the most effective means of educating the young generation (who spend long hours viewing, reading, or listening to the media), the role of the media in directing the young generation has become greater than that of the educational institutions in some cases. This has prompted some media experts to maintain that the media represents the first educational curriculum while the school represents the second. Therefore, when the media outlets use the correct forms of the Arabic language, they become the best source of the language, and in this way they promote the language On the other hand, the media can contribute to the decline of the language.

This study, entitled "Language as a Tool of Thought and Communication," is undertaken because of the important role that language plays in our lives at the emotional and functional levels. It uses the descriptive analytical method, which depends on collecting the research data and then comparing, analyzing, and interpreting it to reach acceptable generalizations. The study consists of three parts, it concludes with some results and recommendations.
\end{abstract}




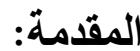

اللغة نسق من الإثارات والرموز تشكل أداة من أدوات المعرفة، وتعدّ أعظم اكتشاف

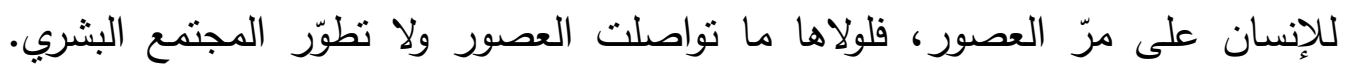

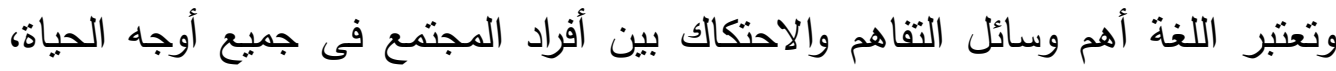

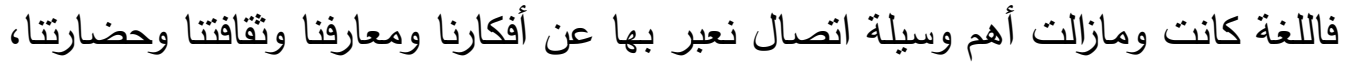
ولما كانت المعرفة هى أساس الحضارة فإن اللغة هى وسيلتها في التعبير، فاللغة رداء أنساء

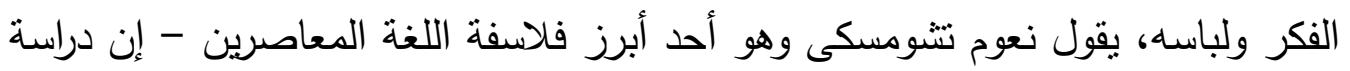

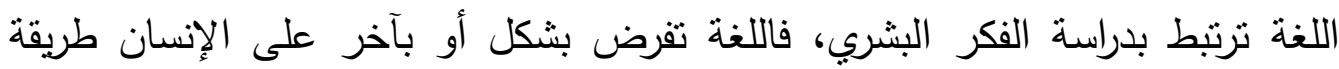

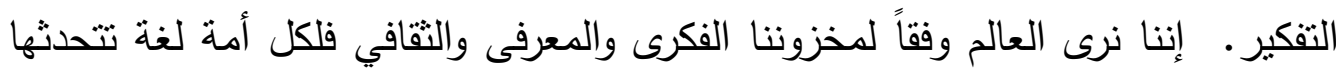
وموروث ثقافي وحضاري، لذا تتعدد الرؤى لهذا العالم الواحد وفقاً لتعدد منظوراتتا.

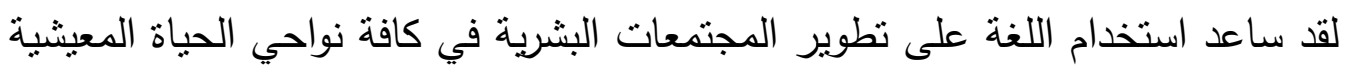

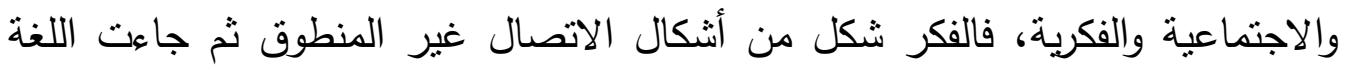

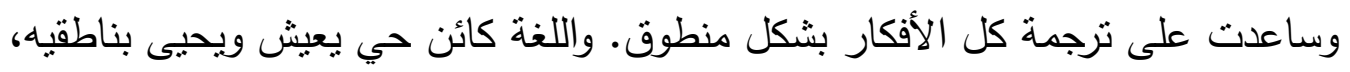

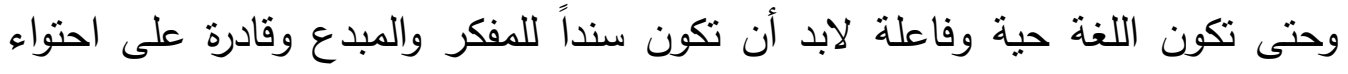

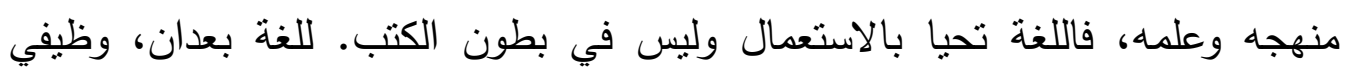

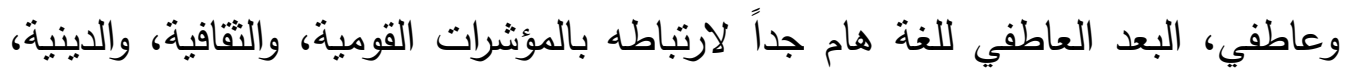

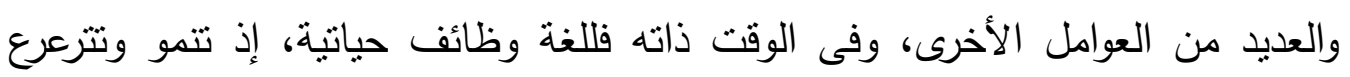

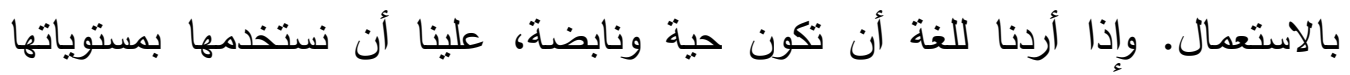
المختلفة فى جميع مناحى حياتتا اليومية(1).

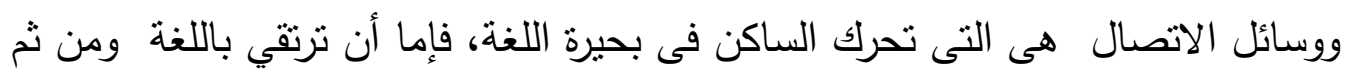
تساهم بذلك فى الارتقاء بالمستوى الجماهيرى ورفع مستوياتهم اللغوية وملكاتهم الفكرية،

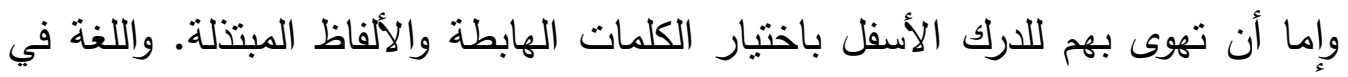

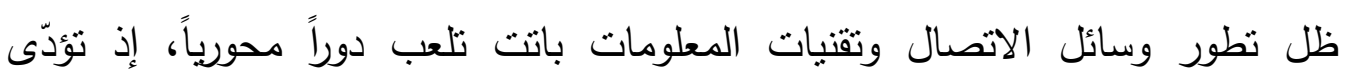


الصياغات اللغوية دوراً خطيراً فى تثكيل القناعات والمفاهيم، وباتت تؤدّى الدور الأساستي في تحديد صور الأمم والثقافات في أذهان شعوب دول فئ العالم الأخرى.

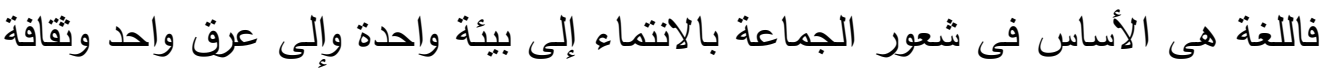

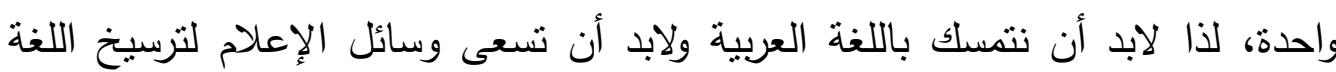
العربية الفصحى لانها هى المعنية بحفظ اللغة وتطويرها وتطوير الناطقين بها ولابد أن تمضى وسائل الإعلام بالفصحى فى نشر هذه اللغة والتعامل بها لتحقيق شخصية الفرد

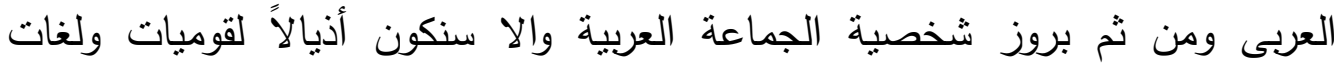

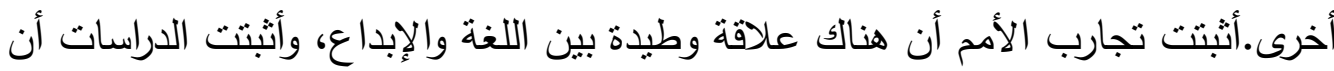
أكثر الدول تسجيلاً لبراءات الاختراع هي الدول التي تدرس العلوم بلغتها.

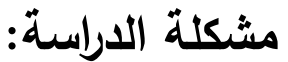

تبلورت مشكلة الدراسة من خلا ملاحظة الباحثة للتراجع المريع للغة العربية واستخداماتها في مجالات الحياة العلمية والعملية بشكل عام، وفى وسائل الإعلام بشكل

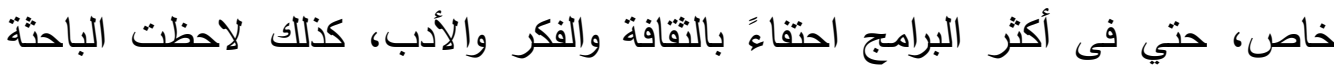

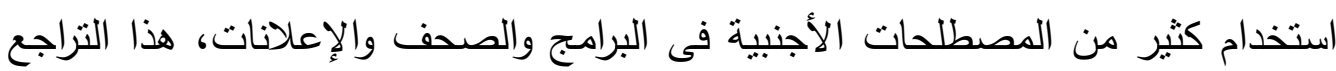

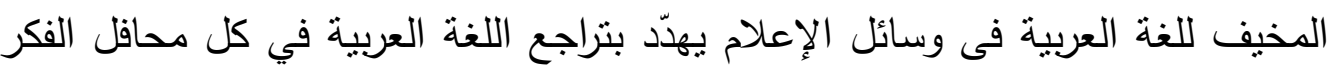
والعلم والإبداع، واللغة لا تعني فقط أصوات وأدة للتبليغ، بل هي على الإعلى مستوى الماضي

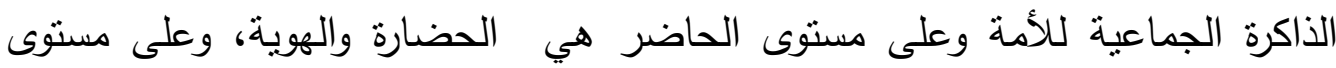
المستقبل هى الطريق نحو الإبداع والعلم، وتواجه اللغة العربية اليوم هجمة شرسة من قبل أعدائها متهمين إياها بالعجز والتقصير عن مواكبة الحياة المعاصرة، جاءت هذه الدراسة

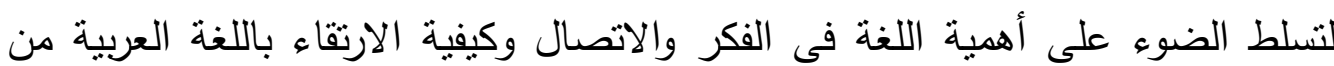

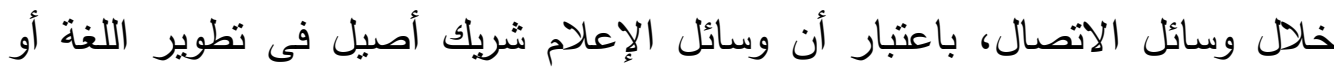


القضاء عليها. لذا نسعى الدراسة للإجابة على سؤالين رئيسين هما، أولاً: ما طبيعة

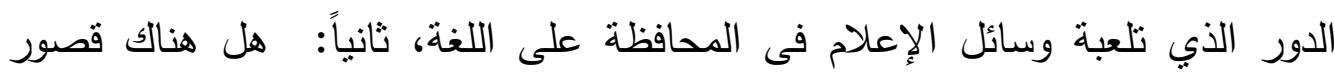
وعجز فى اللغة العربية يقعسها عن أن تكون لغة العصر والمستقبل؟

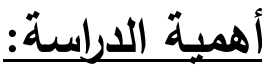

تكتسب الدراسة أهميتها من أهمية اللغة، فاللغة تلعب أدواراً مهمة فى حياتتا على

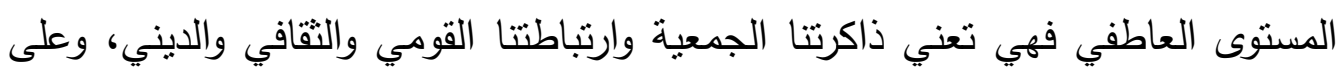

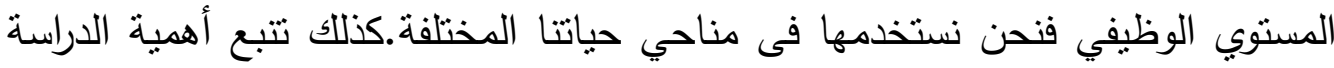
من خلال التأكيد على دور اللغة العربية فى المحافظة على الهوية القومية وعلى الذات الحضارية التي تسمح للفرد بأن يكون صاحب إرادة حرة تسعى لتحقيق غايات خاصة مرتبطة بالثخصية الفاعلة وبالتالي لا يكون مستلبا أو تابعاً.

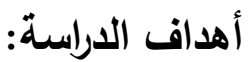

تهدف الدراسة إلى تسليط الضوء على أهمية اللغة للمجتمعات، وتأكيد أن اللغة والفكر صنوان، وأن الإبداع لا يتأتي إلا عن طريق اللغة الأم، كذلك تهدف الدراسة إلى تعزيز

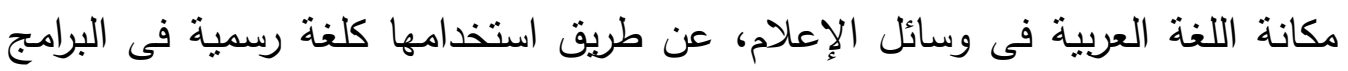

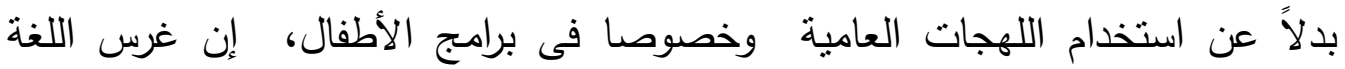

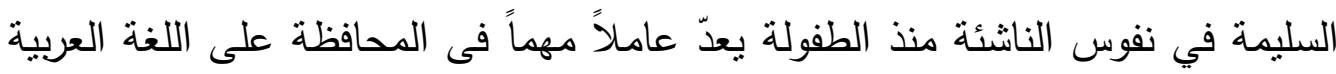

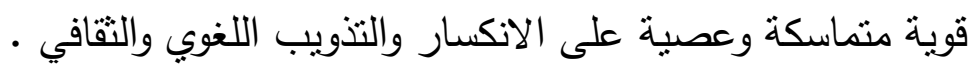

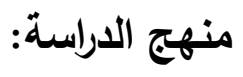

تعدّ هذه الدراسة من الدراسات النظرية، استخدمت الباحثة المنهج الوصفي التحليلي

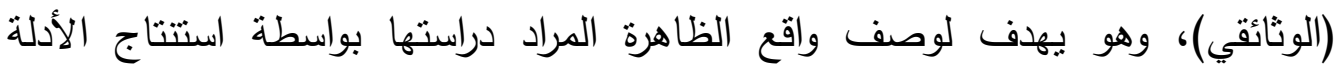

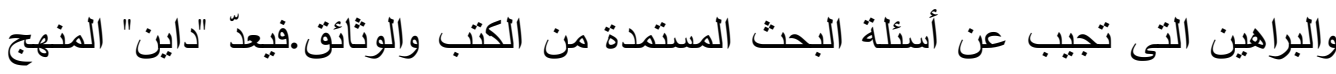

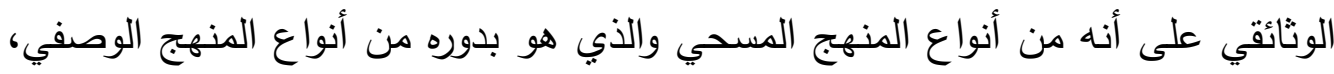

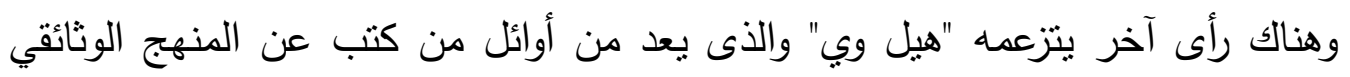


ويعتبره منهجا قائما بذاته حيث قال " عندما يريد الباحث أن يدرس وقائع وحالة ماضية

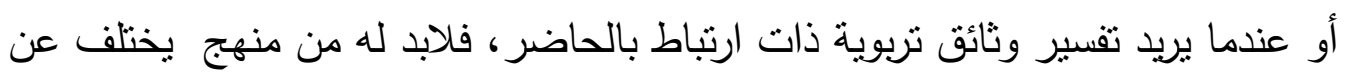

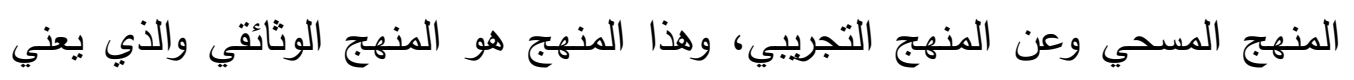

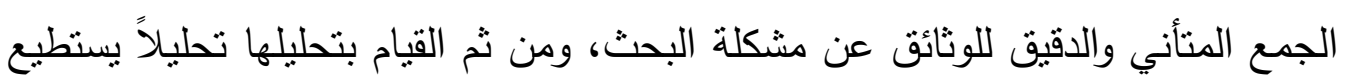

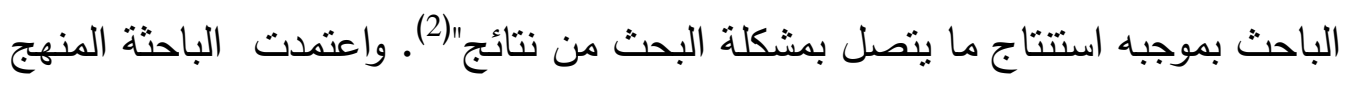

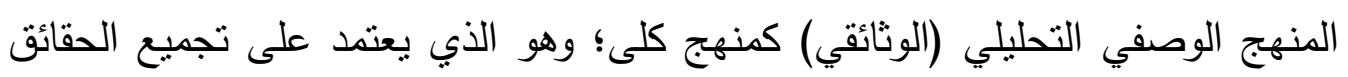
والمعلومات ثم مقارنتها وتحليلها وتفسيرها للوصول إلى تعميمات مقبولة.

مصطلحات الاراسة:

مفهوم اللغة: هي تلاك الأصوات التي يصدرها جهاز النطق الإنساني وتصل إلى الأنن،

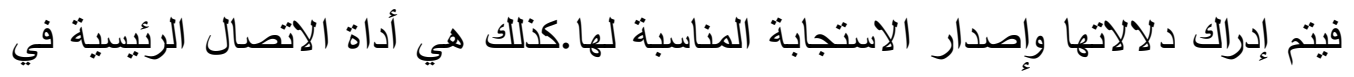

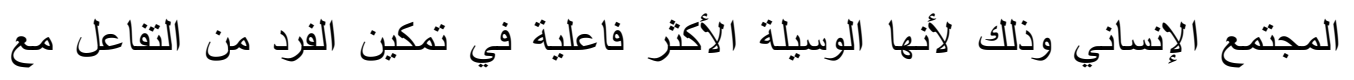

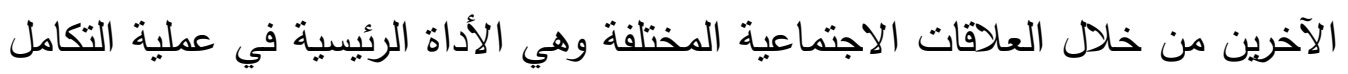
والتكيف والبيئة).

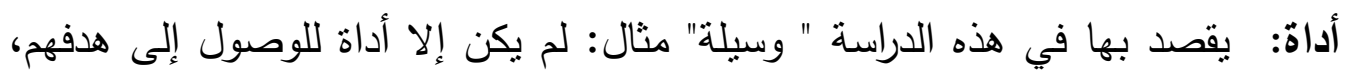
اللغة هي أداة التعبير عن الفكر. فكر: يقصد به اعمال العقل في المعلوم للوصول إلى المجهول، وهو مصطلح ينت

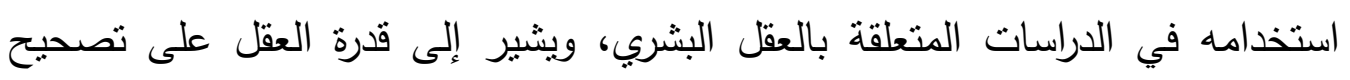

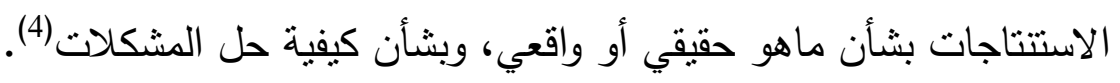

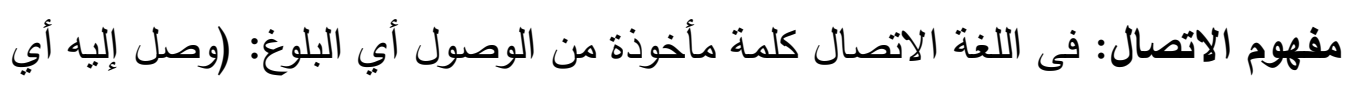

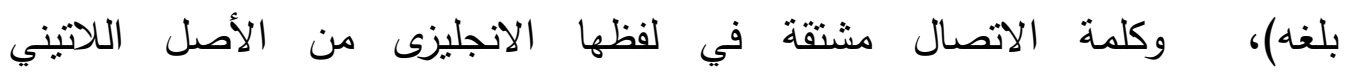
(Communes) نحاول أن نشترك سويا في معلومات وأفكار أو مواقف واحدة)(5). 


\section{المبحث الأول}

\section{اللغة أداة تواصل}

لقد كانت الكتابة قبل الحروف تتم عن طريق الرموز والنقوش والرسومات وأصبحت

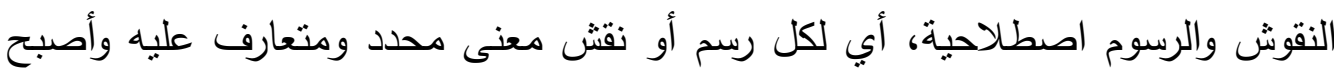

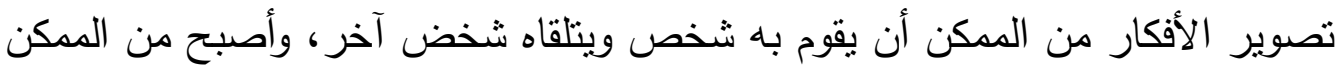

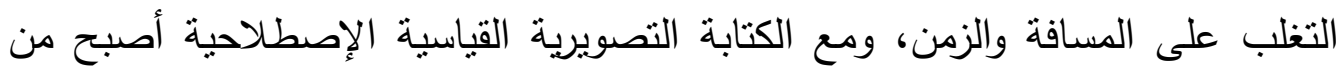
المكن فلك الرسائل التي يبعث بها أناس من مسافات بعيدة أو حتي أناس ماتوا بالفعل.

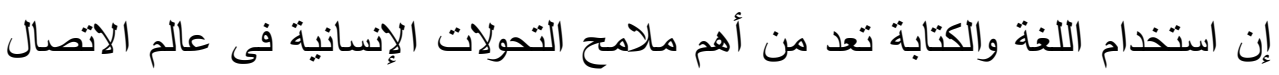

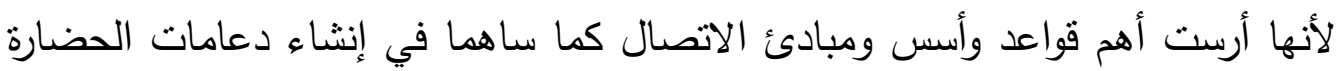

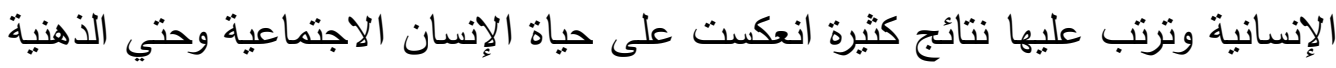
والعقلية وأسلوب التفكير، واختراع الطباعة حوالي عام (1440) على يدان الألى الألماني جوتتبرج، كان داعماً كبيراً لاستخدامات الكتابة المختلفة، وتوسعت الكباعة الكتابة وانتشرت وأصبحت أساسا للنطور الحديث فى كل مظاهر الحير الحياة المختلفة. تعد حروف الكتابة أحد أهم منجزات الجنس البشرى فى كل العصور إلى جانب اختراع

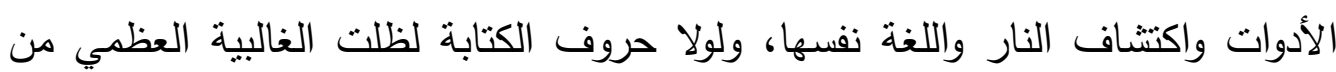
سكان العالم تعاني الأمية (6). (لأن

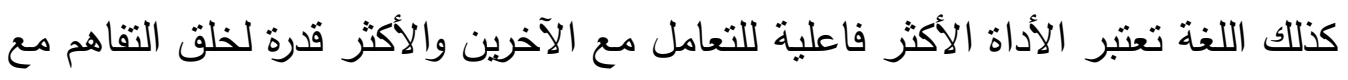
بعضنا البعض، وتبادل المعلومات والخبرات، والأكثر مرونة في الكتسابنا للمعرفة والثقافة الأنة

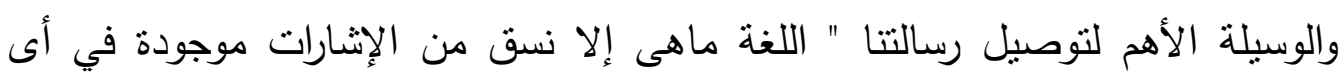

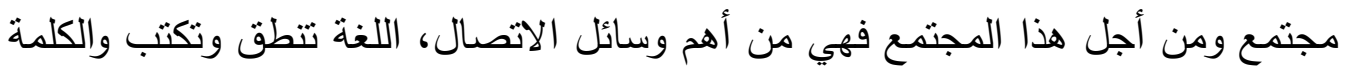
المجهورة، تسبق المدونة لأن الناس تكلموا قبل أن يكتبوا"(7).

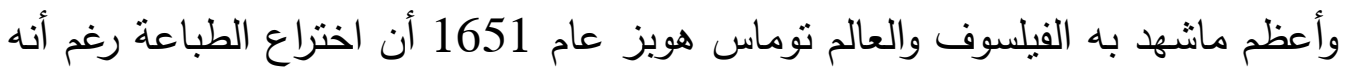

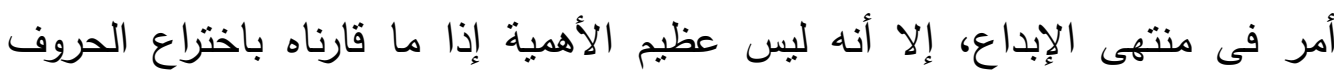


الهجائية، لكن الكتابة تعتبر اختراعا مفيدا لاستمرار ذاكرة الزمن الماضي، لكن أكثر

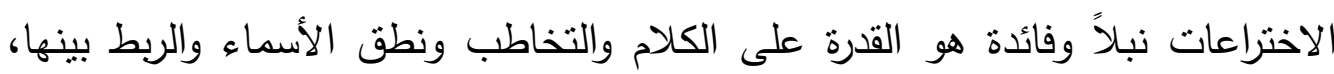

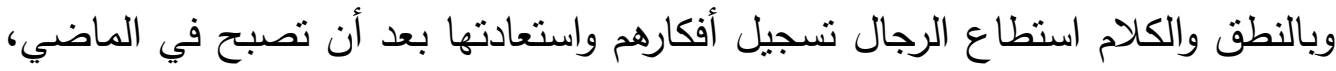

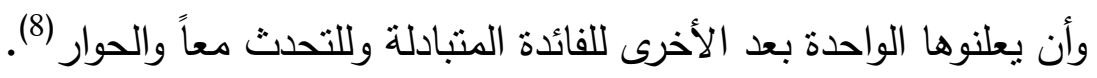
لقد ساعد استخدام اللغة على تطوير المجتمعات البشرية في كافة نواحي الحياة المعيشية

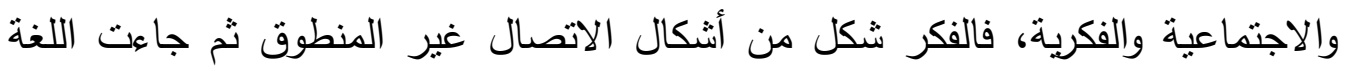
وساعدت على ترجمة كل الأفكار بشكل منطوق.

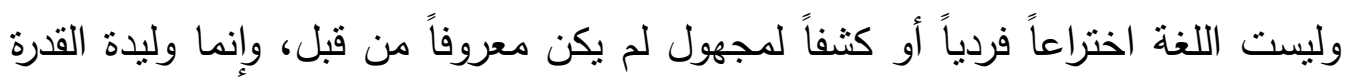

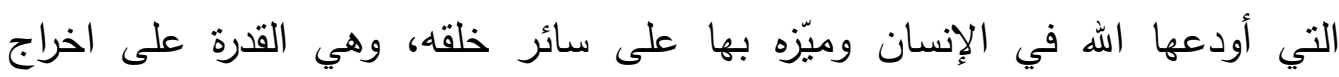

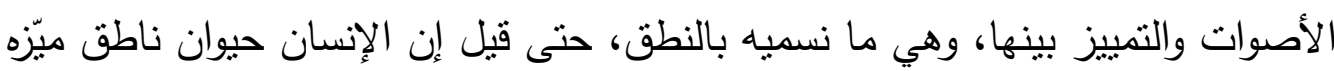

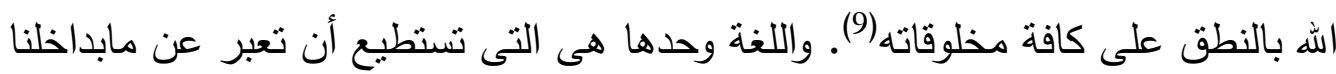

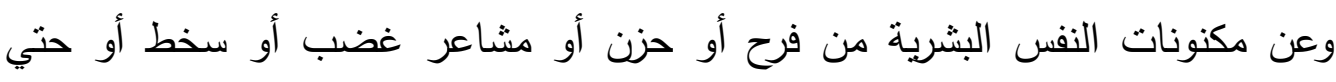

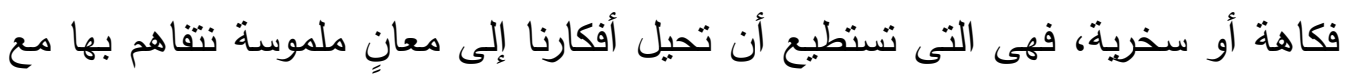

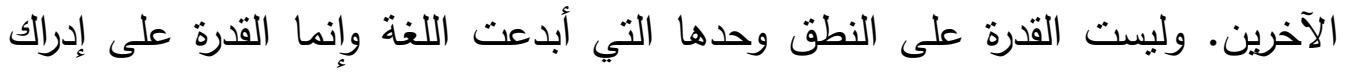

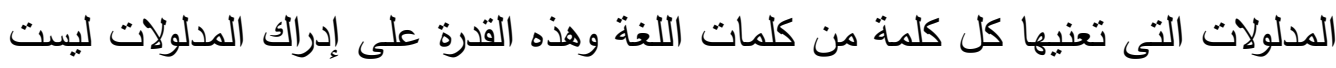

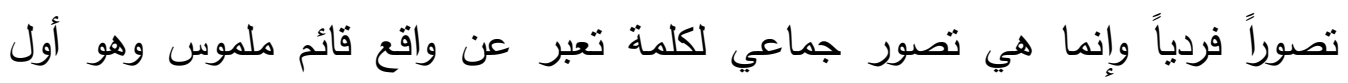

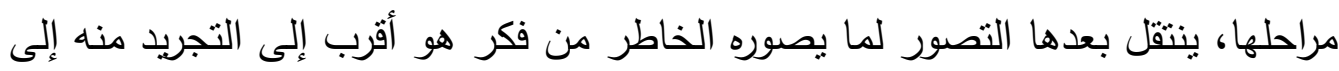

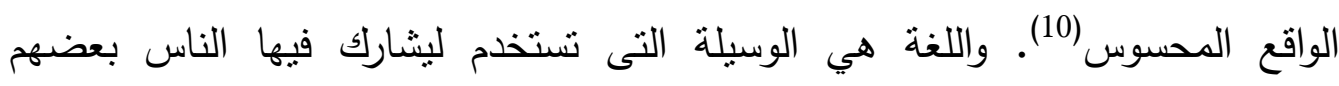
البعض لفهم وإدراك المعاني التى هى في الأصل ترجمة لما يدور فى عقلنا من تفكير. وعليه فإن اللغة هى الوسيلة الأمثل للتعبير عن أفكارنا.

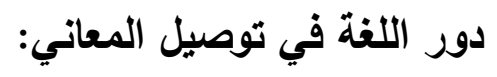
الدفاهيم هي مجموعة من الصفات ذات المعنى لبعض نواحى الواقع التي يمكن التعرف التهف

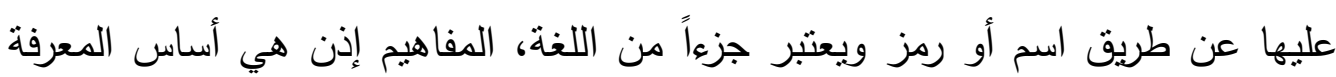


ونقطة البداية لنظرية الاتصال، ويبدو واضحاً أن أهمية الاتفاق على المعاني لمعرفة العالم الذي نعيش فيه كما يقول افلاطون لايعتمد فقط على مانلمسه بحواسنا، وإنما اتفقنا

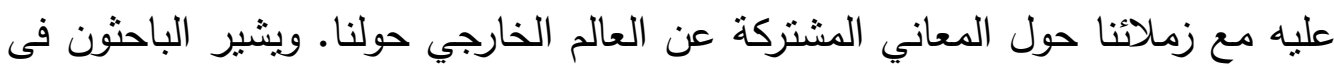

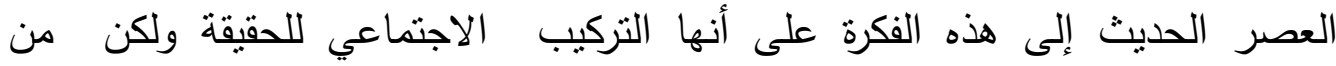

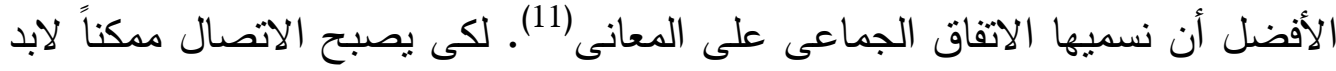

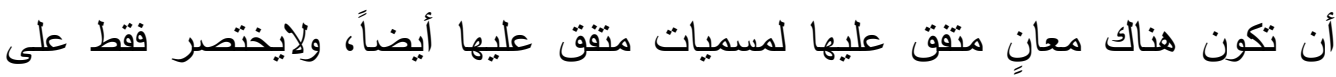

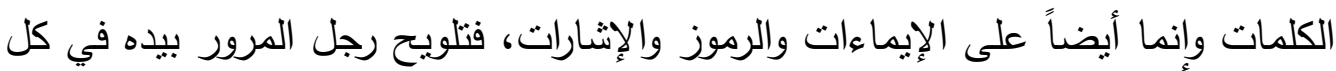

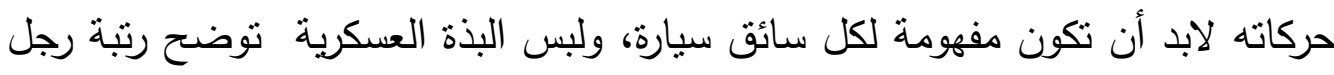

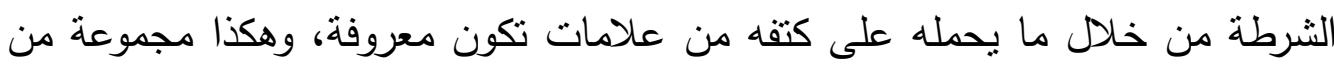

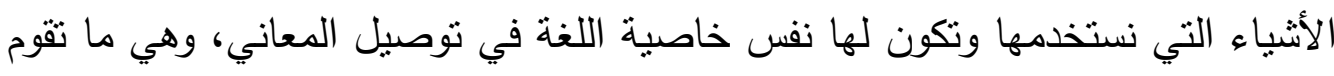

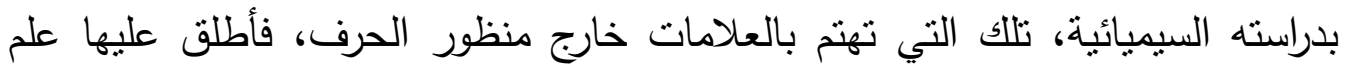

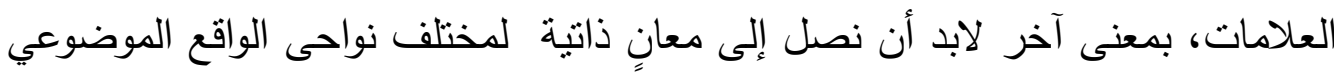

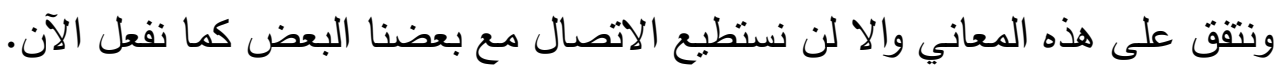

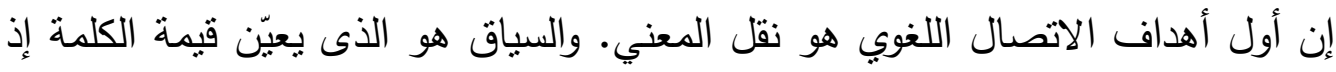

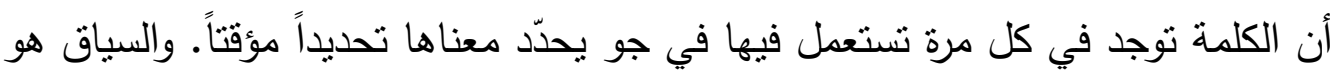

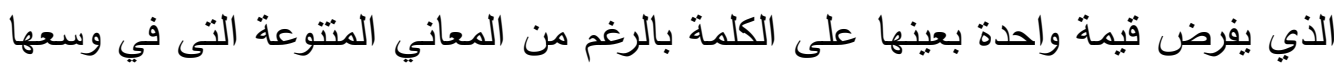

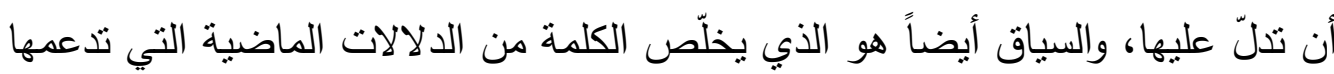

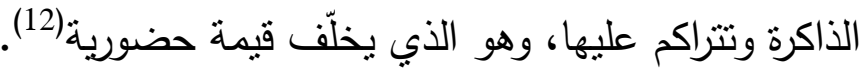

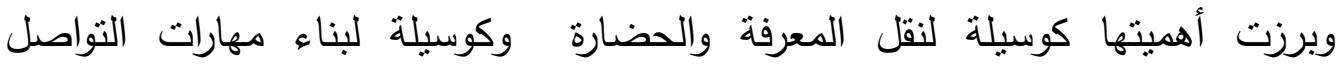

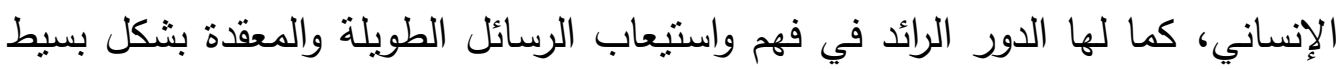
وسلس كان يصعب مع أنثال الاتصال السابقة بدون استخدام اللغة.

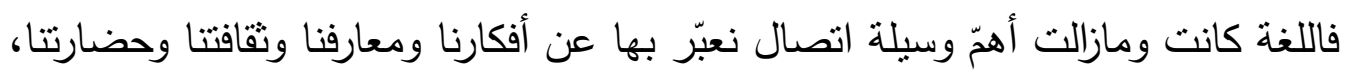
ولما كانت المعرفة هى أساس الحضارة فإن اللغة هي وسيلتها في التعبير، فاللغة رداء 
الفكر ولباسه، وكلّ تطوّر يحصل فى المجتمع يتردّد صداه من خلال مؤسسة اللغة، وكلّ المجتمعات استخدت مختلف وسائل الاتصال لإبراز شكلها الحضاري من رسومات

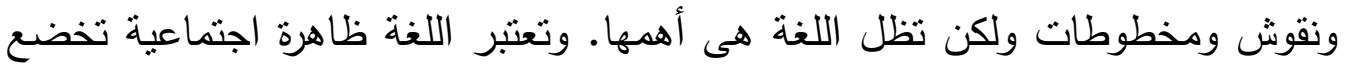

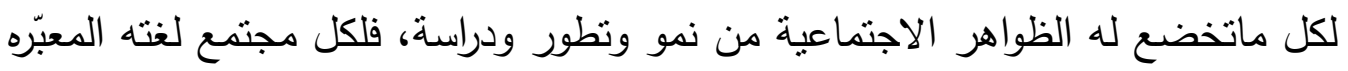
عن ضميره وحاجاته وواقعه فتمايزت اللغات كما تمايزت المجتمعات.

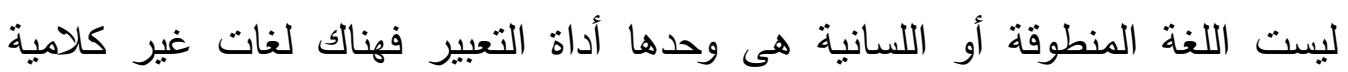
كالاثشارات والصور المطبوعة وغيرها ولكن تظل اللغة المنطوقة هى وسيلتنا الأساسية لنقل المعلومات في المجتمعات الإنسانية وهى الصلة بين الفكر والمعرفة. إن الناس لا لا يعيشون فقط في نطاق عالم الأثياء الذي يحبط بهم وفي نطاق الحضارة والحياة

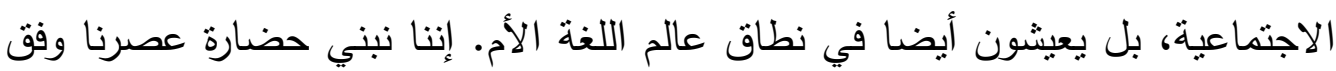

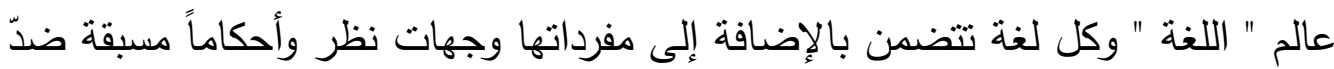

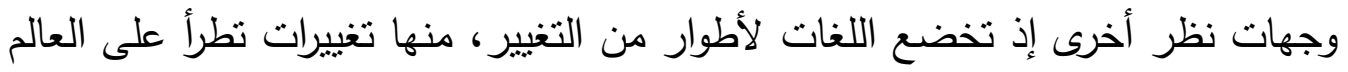

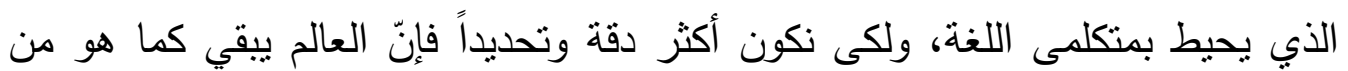

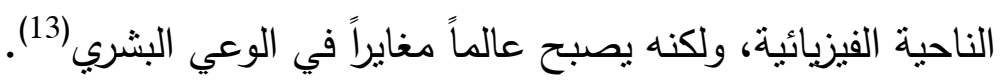

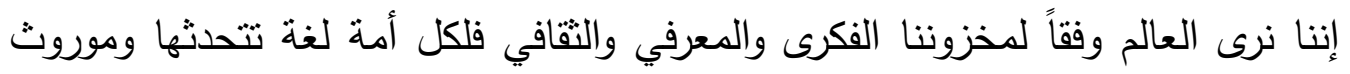
نقافي وحضاري، لذا تتعدّد الرؤى لهذا العالم الواحد وفقاً لمنظورنا المتعدّد وربّما المنباين

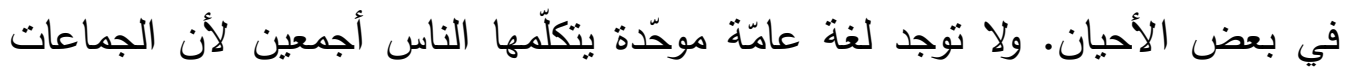

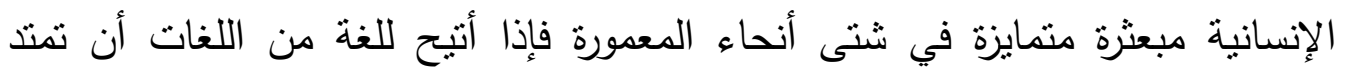

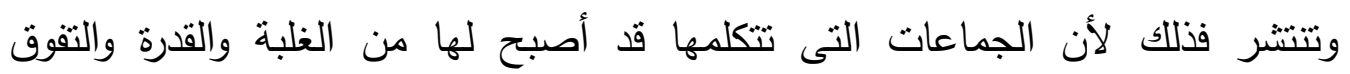
الحضاري ما يجعل سلطانها غالباً على غيرها(14). ويرجع انتثار عدد من اللغات التات

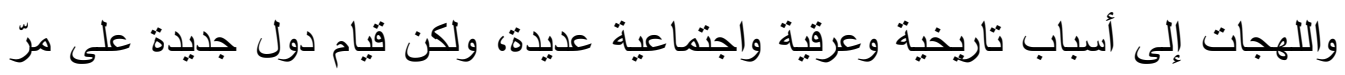

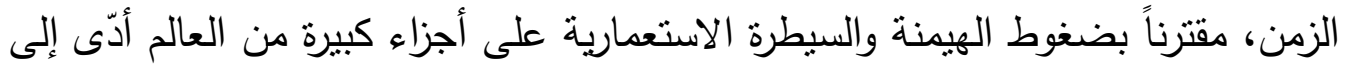


تعديلات لغوية في كثير من الأحيان، الأمر الذى أدّى بدوره إلى اختفاء تدريجي لبعض

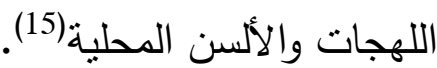
إنّ الحضارة لا تتعكس في شئ مثلما تتعكس في الكلام واللغة، حيث يذهب بعض لهض

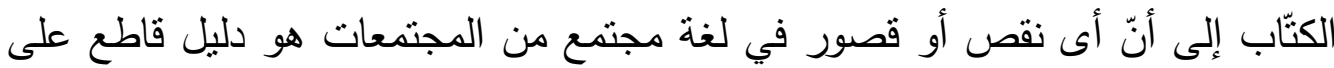

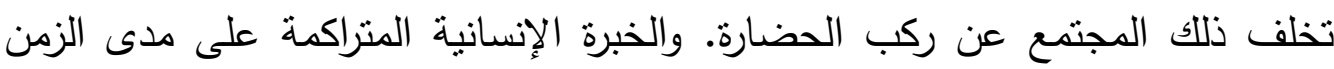
نعبر عنها بأى شكل سواء كان هذا التعبير كلاما أو رسوما أو نقوشا كالتي تركها

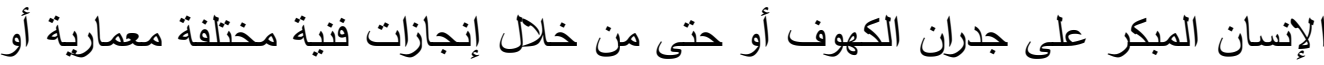
حركية كالرقص والتنثيل الصامت، فاللغة حتى في معناها الضيق الدقيق الذي يقتصر

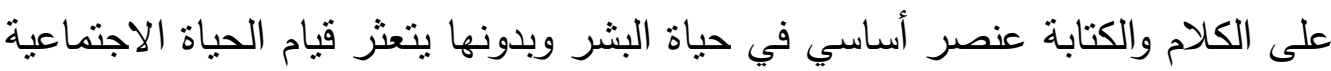
المتماسكة وبالتالي يستحيل قيام الحضارة بكل ماتعنيه هذه الكلمة من نظم اجتماعية

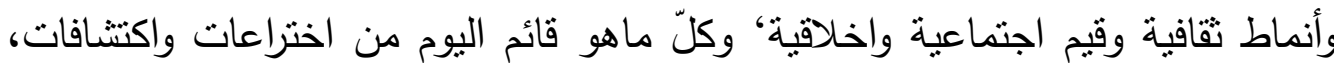
ذللك لأنّ اللغة هى أداة التفاهم والإعلام واللذين هما أساس التعاون بين أفراد الجماعة(16). وذيوع لغة أمّة دليل على تفوقها الحضارى والفكري، ولقد كان الفضل لتقدم

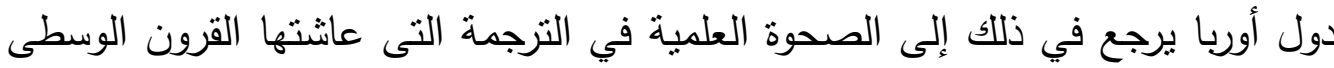
وكانت فيها ترجمات الفلاسفة العرب ابن سيناء وابن خلدون والفارابي وابن هيثم وغيرهم من فلاسفة العرب وعلمائهم المرجع الوحيد للعلوم الطبيعية والعلمية والاجتماعية، أي أنّ التّاء

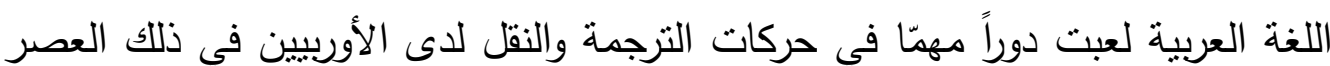
وهذا دليل على أنها كانت قادرة على التعبير عن منطلبات ونقل كلّ الحضارات القديمة فكان للعرب مجد وحضارة، وهذا يدلّ على أنه لايوجد عجز في لغتهم يمنعهم من اللحاق بركب الحضارة، وعندما بزغ فجر اللغة الفرنسية في القرن التاسع عشر كانت فرنسا تتربع عرش الفكر العالمي من فن وثقافة وأدب فأصبحت اللغة الفرنسية هى أهم لغة لمن بريد أن يلحق بركب الحضارة(17). 
كما أمّن الاستعمار لعدد قليل من اللغات الأوربية فرص الانتشار في الكرة الأرضية

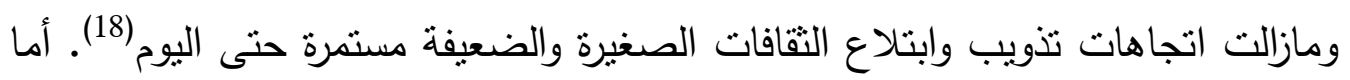

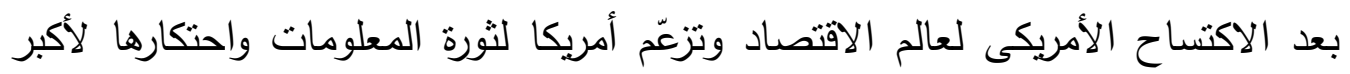

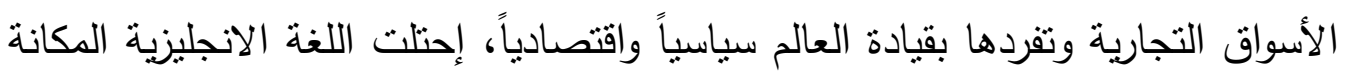
الأولى وأصبحت هى وحدها التى تسنطيع أن تصلك بعالم التكنولوجيا والاتصالات

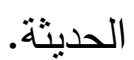

إن الفهم الجيّد لطبيعة ودور اللغة فى نقل الإرث النقافي والمعرفي للآخرين يلعب دوراً مههاً فى تفعيل عملية الاتصال، ويحدث الأثر المراد تحقيقه من العملية الإنية الاتصالية.

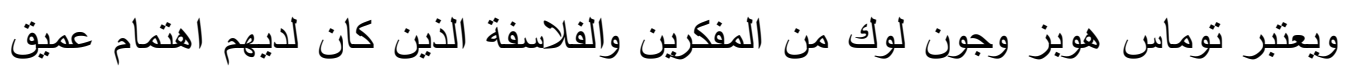

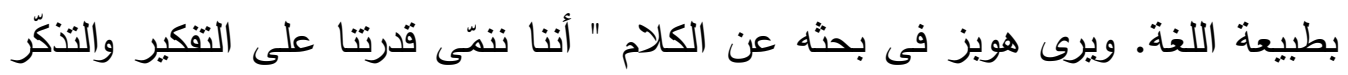

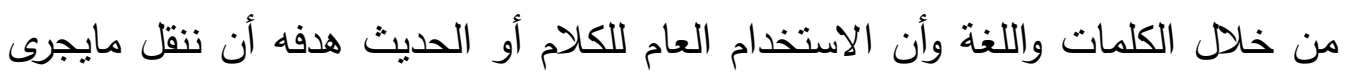

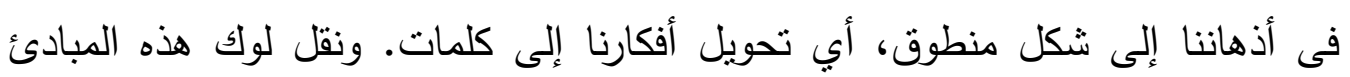
خطوة أخرى إلى الأمام وجعل اللغة هي أساس النظام الاجتماعي" (19).

\section{المبحث الثاني \\ أزمة اللغة العربية في وسائل الاتصال}

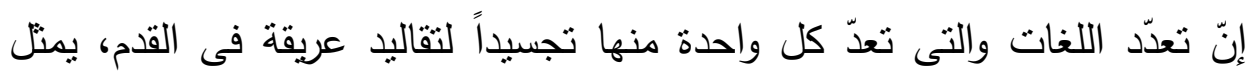

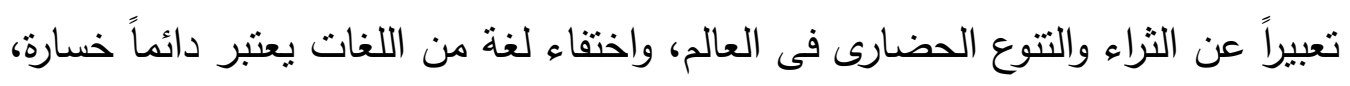

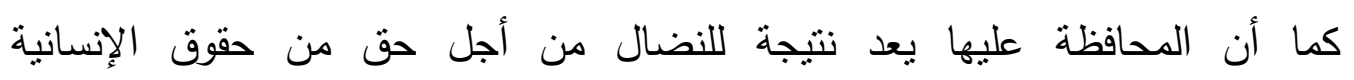

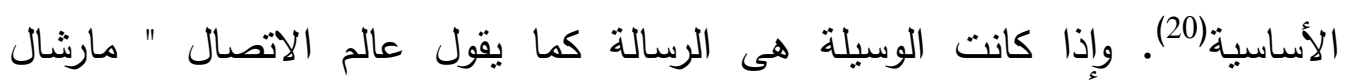

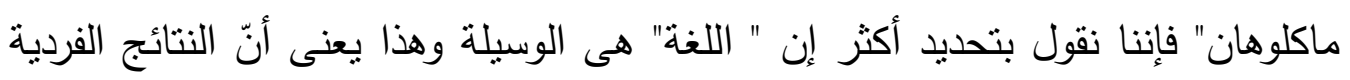

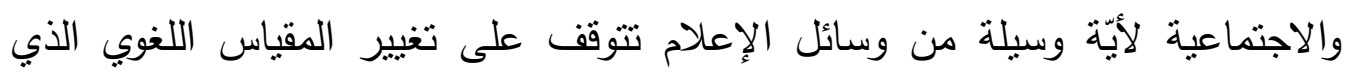


تحدثه كلّ تكنولوجيا جديدة ومن أجل ذلك يذهب ما كلوهان إلى أن " مضمون" أي وسيلة دائما يعدّ وسيلة أخرى (21). ولا يثكل التخوف من تقنية جديدة تخوفاً من الوسيلة فى حد ذاتها ولكن ماتحمله هذه

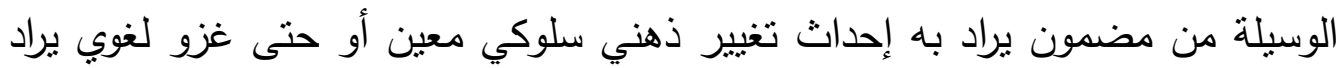
به فرض لغة معينة وفرض هيمنتها على بقية اللغات. واللغة هى ترجمة للفكر ، وتطور اللغة معناه التطور الفكري لذا كان الارتباط السببي بينهما واجب فأهمية اللغة تكمن فى لهى

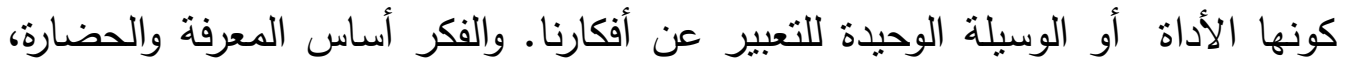

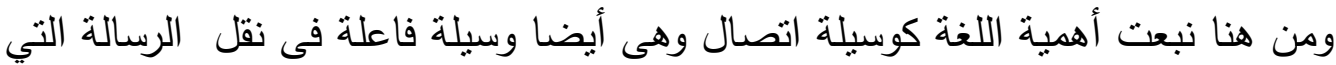
بريد المرسل بثها وهي مؤشر خطير ومهم ودال على أهمية هذه الأمة أو تلاك

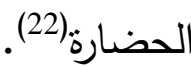

الغزو الثقافي والفكري الذي تتعرض له كلّ القوميات ومن بينها الأمة العربية فهو قبل أن

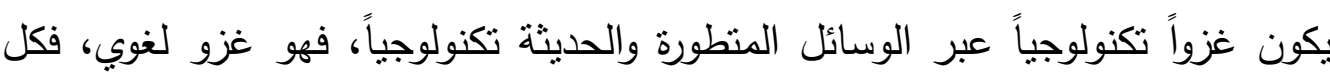
التدفق المعلوماتى الهائل فى ظل ثورة المعلومات والحاسبات الآلية تسيطر على غالبيته العظمي اللغة الإنجليزية إذ تمثل القدح المعلّى مقارنة مع اللغات الأخرى.

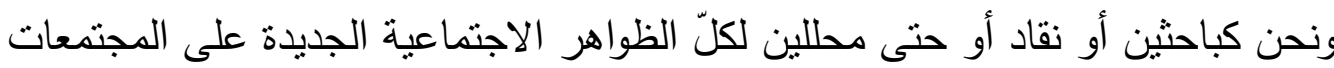

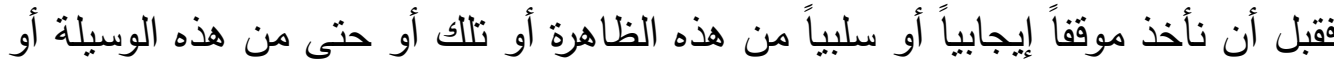

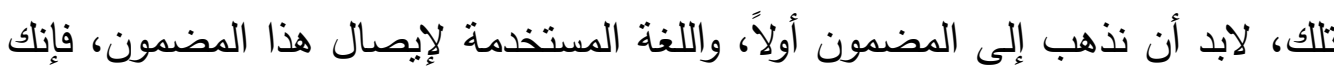

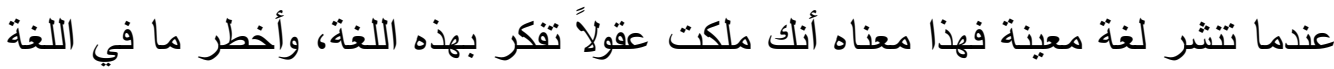

$$
\text { هو السبطرة على الفكر . }
$$

وكان ذلك مبدأ استعمارياً ففى السابق كانت سياسة المستعمر " إذا أردت أن تغزو دولة فاجعل شعبها يتكلم لغتلك، فإذا أتقن شعبها استخدام لغتك فيعنى هذا أنك حكمته" ويدلّل على ذلك النقاش الذي دار بين الجنرال " ديجول" وبعض الساسة الفرنسيين حول كيفية الحفاظ على الجزائر المستقلة داخل التأثير الفرنسي، قال له البعض: ينت ذلك بالإبقاء 
على قواعد عسكرية، وقال له البعض الآخر : ينت ذلك بإبقاء الاقتصاد الجزائرى مستقبلا

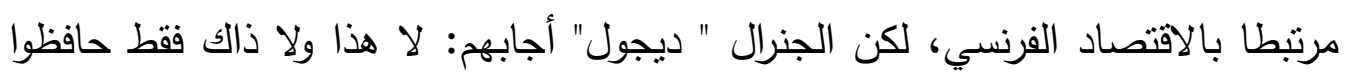

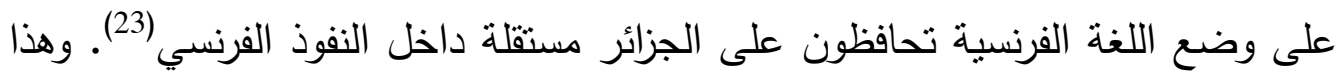
يعنى أنّ البعد الثقافي والفكرى لم يكن غائباً على المستعمر السياسي وأن هيمنة اللغة الفئ

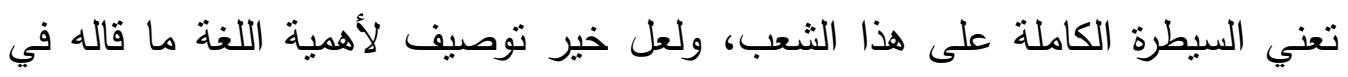

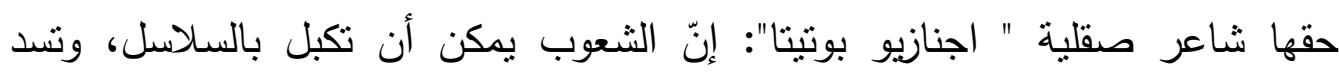

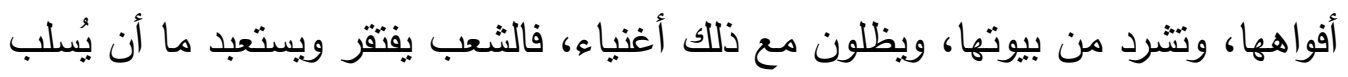

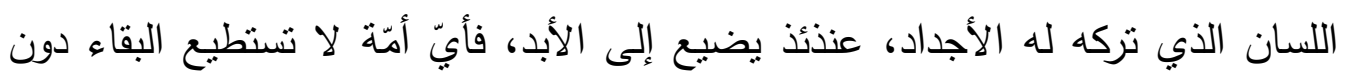
لسان يعبر عن ذاتهان(24). ونحن الآن لسنا في عصر الاستعمار السياسي ولا الامبراطورية التي لا تغيب عنها

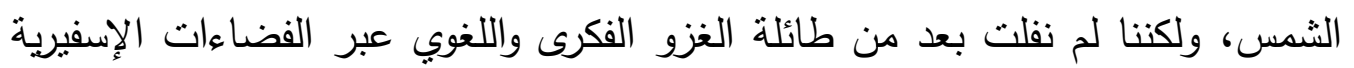

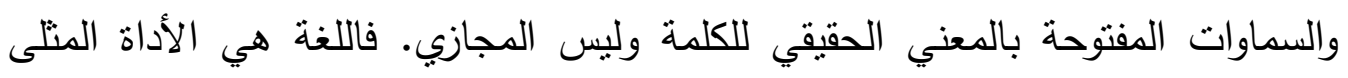

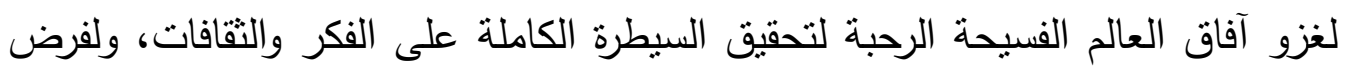
ثقافة واحدة وحضارة واحدة ولغة واحدة، وبذا تكون السيطرة لأمّة واحدة وحضارة واحدة التها

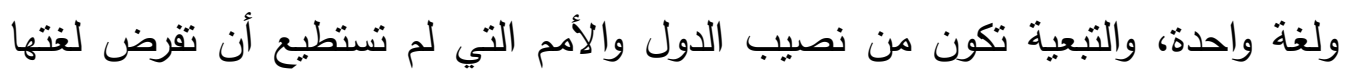
وتقافتها وحضارتها، ليس فقط أن تفرض بل أن تحافظ على لغتها وهويتها. إن التطوّر

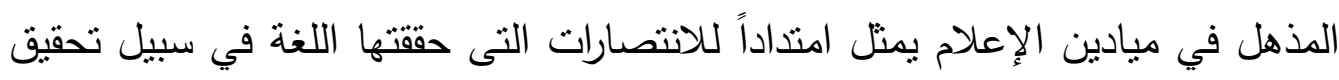

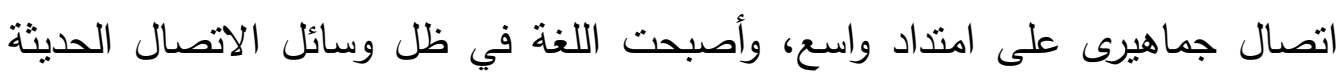

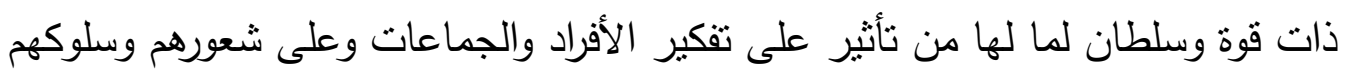

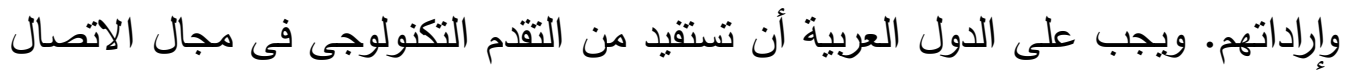

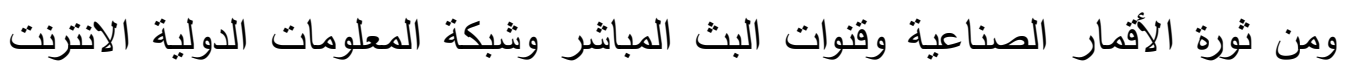

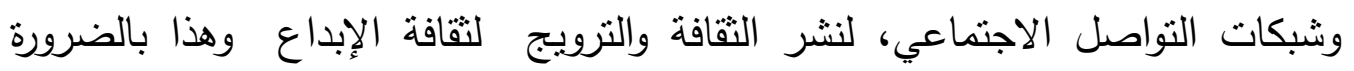


يفرض الارتقاء بمستوى اللغة العربية والتي كانت في يوم من الأيام هى لغة الترجمة التي نقلت الفلسفة اليونانية للغرب بترجمة عربية للفلسفة والفكر الإغريقي.

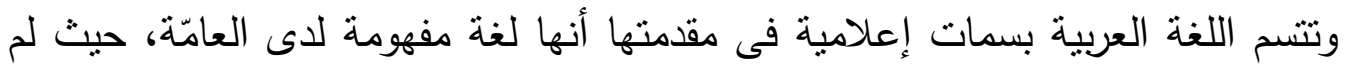

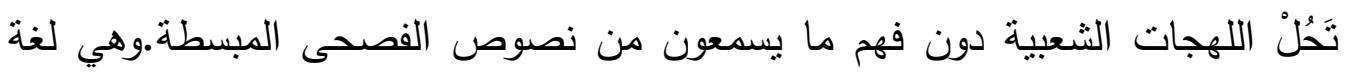

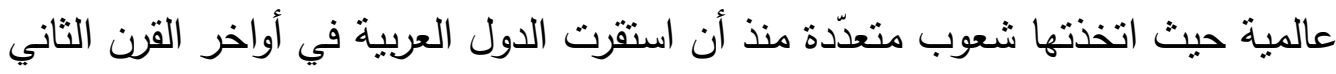

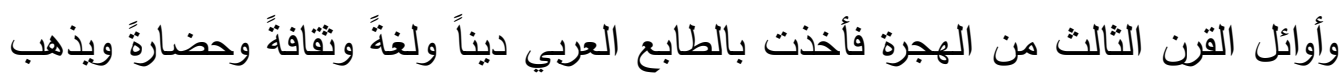

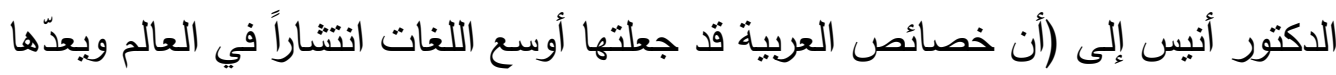

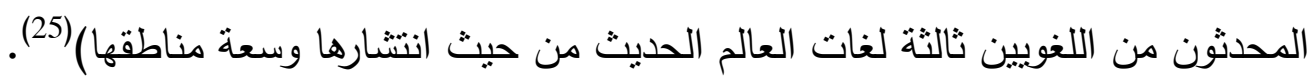

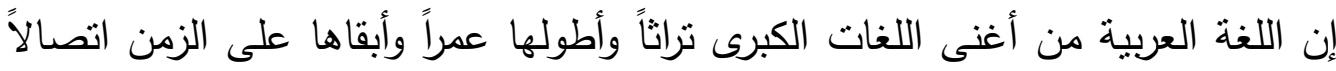

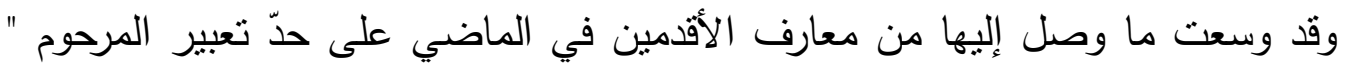

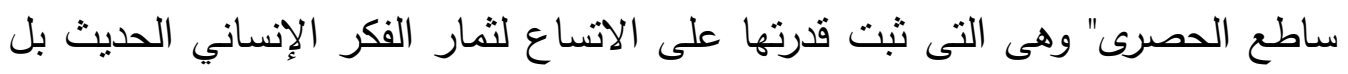

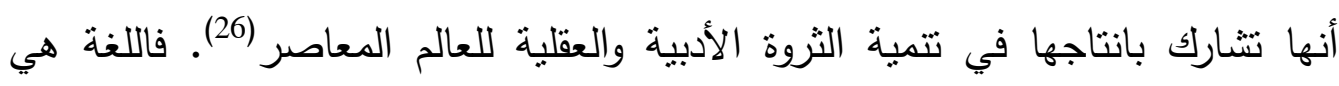

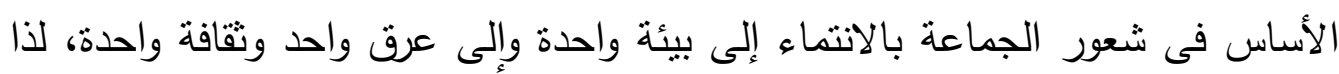

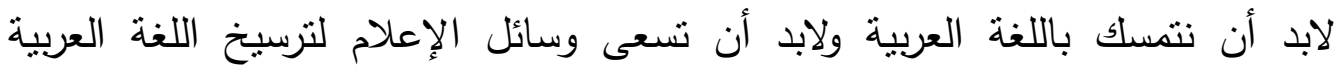

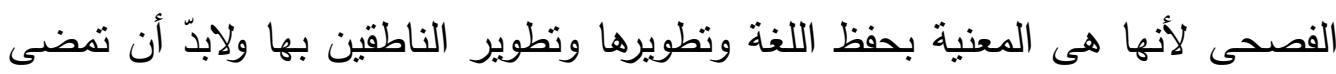

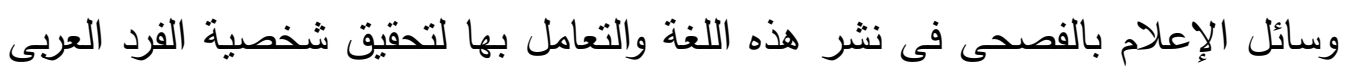

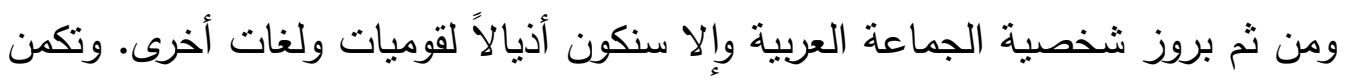

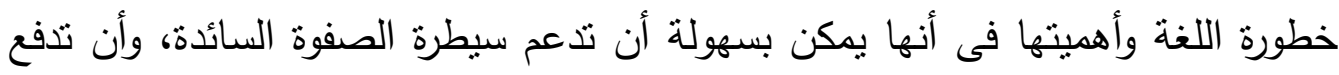

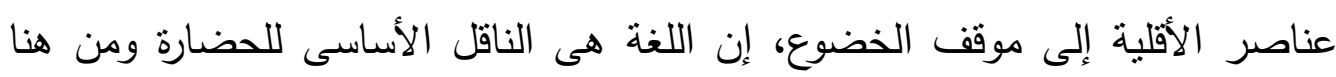

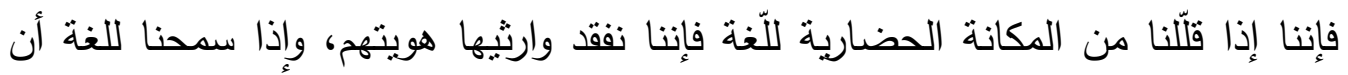
تتلاشى فإن النتيجة هى خسارة ثقافية لا يمكن تعويضها (27). ومع تنامى وسائل الاتصال

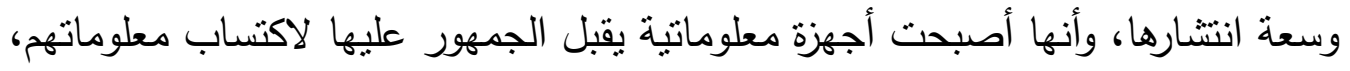

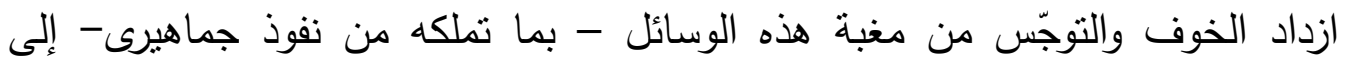


معاول تتسف اللغة، وتفسد اللسان، وتهوى بالذوق اللغوب إلى الحضيض(28)، فعلى سبيل المثال الناظر فى الصحف يجد على صفحاتها دعايات إعلانية قد كتبت باللغة العامية المبتذلة، وهذا النوع من الإعلانات نراه منتشرا فى كل مكان فى الصحف فى

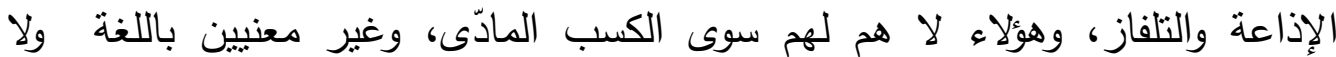
جمالياتها ولا تأثنراتها، ودون أن يدركون هم يساهمون فى إفساد الذوق العام، وفى حديثه عن وظيفة التلفزيون فى المتمع، يحذر الباحث " رينيه شنكر" من مغبة انحراف

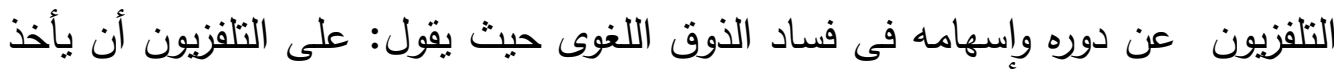
بعين الاعتبار أنه وسيلة ترفيه، بالإضافة إلى غايات أخرى، أنه فى هذا المجال وفى الدى

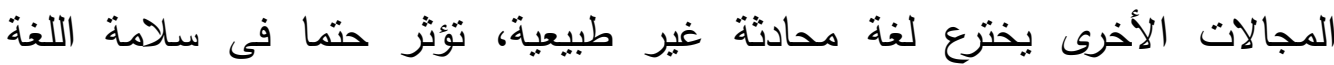

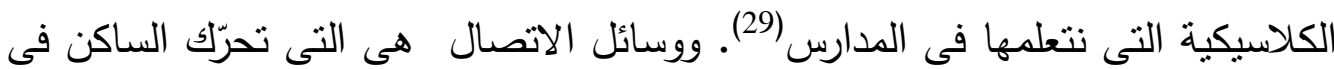
بحيرة اللغة، فإما أن نرتقي باللغة ومن ثم تساهم بذلك فى الارتقاء بالمستوى الجماهيرى

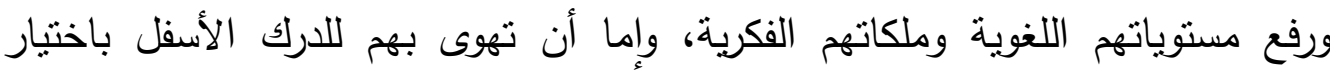
الكلمات الهابطة والألفاظ المبتنلة، ففى غياب فضاءات التثقيف والتزفيه بظل التلايفزيون فى الغالب هو الملاذ الأكثر إقبالا فى أوقات الفراغ بالنسبة للجمهور، اللغة في التلفزيون

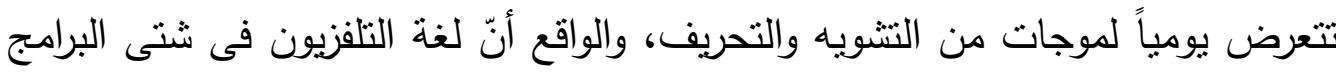
والأفلام تخترق حرمة اللغة الخاصة النى يكوّنها كل إنسان لنفسه وتتكوّن فيه من خلال عائلته وبيئته ووطنه (30). واللغة العربية تتمتع بميزات تجعلها جديرة بأن تكون لغة إعلام

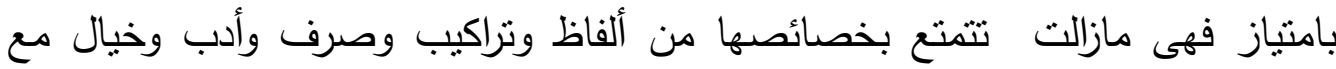

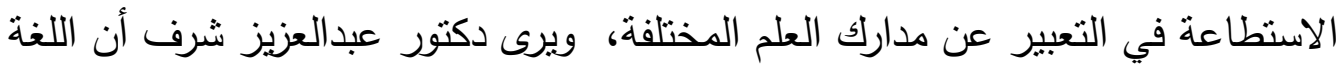
العربية لغة إعلامية تقوم على نسق الفن الإعلامي الحديث مؤكدا على الصفات التى ينبغى أن تتحلى بها لغة الإعلام ومنها البساطة والمرونة، ولا بطلب من رجل الإعلام

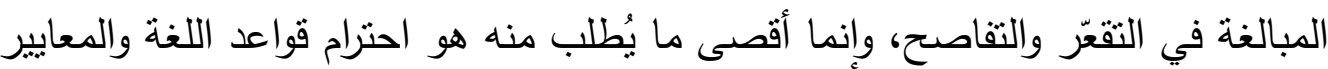

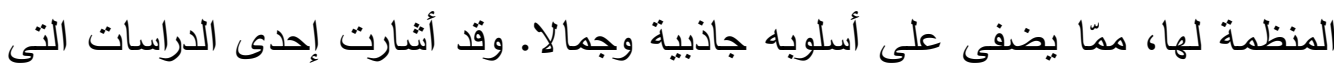


حاولت رصد بعض البرامج التى تبثها بعض الإذاعات والتلفزيونات العربية في تليية

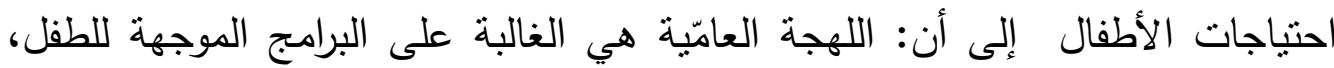

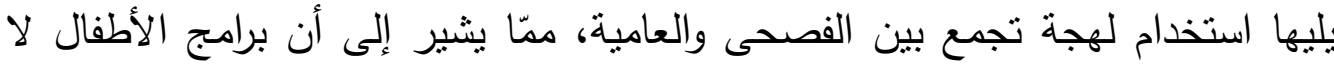

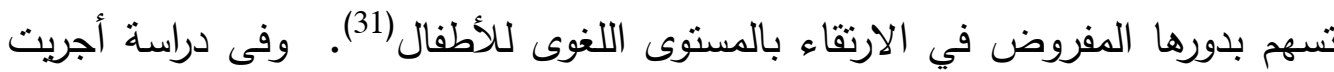
على عينة من الثباب الجامعى حول دور الفضائيات العربية في نشر الثقافة العربية، ذكر نسبة (45\%) من المبحوثين أن القنوات الفضائية العربية أدّت إلى تخريب الذوق

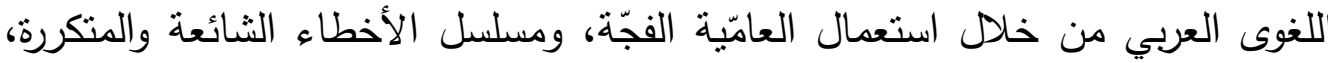
والتوظيف السيّئ لأسماء البرامج، إضافة إلى ضعف مستوى مقدميها (32). المبحث الثالث

\section{اللغة العربية واتهامها بالقصور}

وهناك من حاول الوقوف في وجه اللغة العربية واتهمها بالقصور وحاول النيل منها بادعائهم بصعوبة تعلّمها واتقانها وتعقيد نحوها وصرفها وتعذّر الالمام بها وتثابك قواعدها الإملائية وهنالك من ادّعى أنّها لا تتماثشى ومقتضيات العلم الحديث والتكنولوجيا

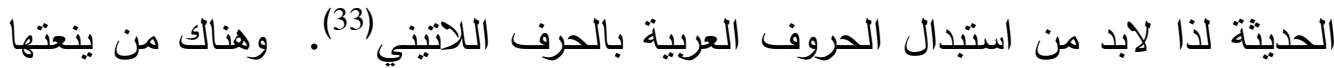

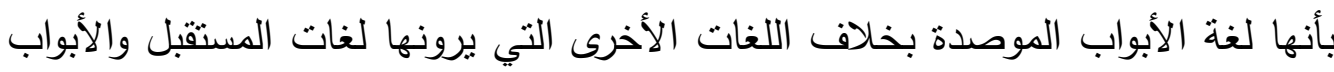
المشرعة، تؤكد الكاتبة المغربية " إكرام عبده" أن العيب ليس في اللغة العربية حاملة العلوم والآداب والفكر طوال تسعة قرون والتىى كان يمتلكها " ابن رشد" واخترق بها لكانه

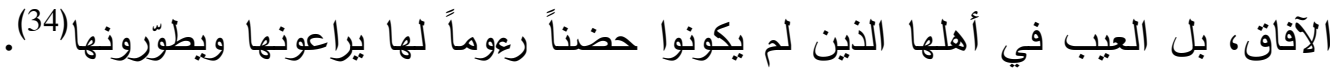
ومن يدّعى أنّ الفصحى لا تلبى الحاجة أو أنها صعبة فحسب القائل بهذا الرأى أن يقرأ

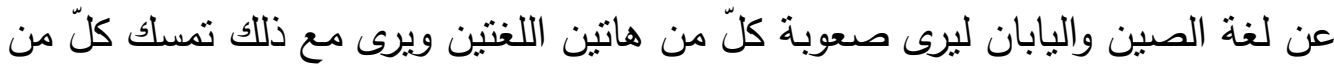
الثعبين الواعيين بلغتهم... يقولون إنّ القارئ العادي يحتاج لكي يتمكن من قراءة جريدة لياني

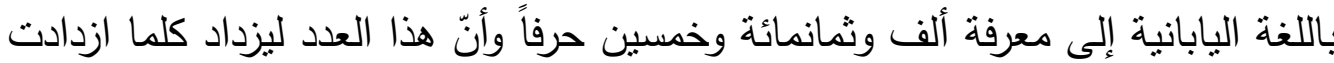

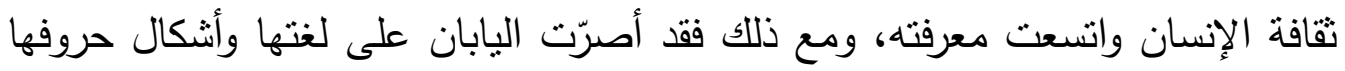


بل صور حروفها لأنها كما قالت لجانهم التربوية تراث الأجداد والثقافة اليابانية هو عنوان

الثخصية اليابانية(35).

إن دولاً ومجتمعات كثيرة تخثي على لغتها من الضياع والاندثار وتبذل جهودا واسعة ومختلفة الأشكال من أجل الحفاظ على لغتها وتخصنص من من أجل ذلاتك أموالاً طائلة

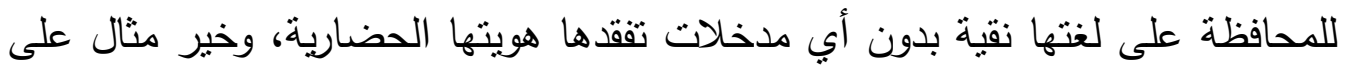

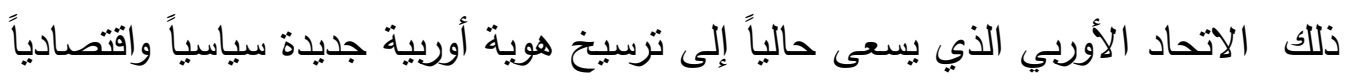

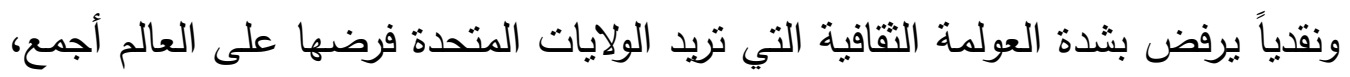

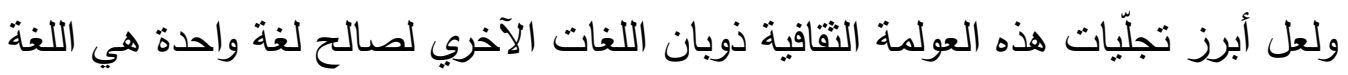

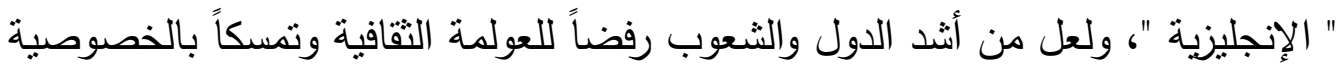
الثقافية هي فرنسا التي تتمسك بموقف متشدد في هذا الصدد، واتخذت إجراءات قانونية

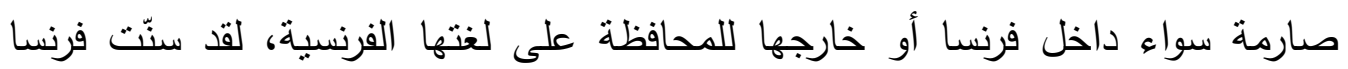

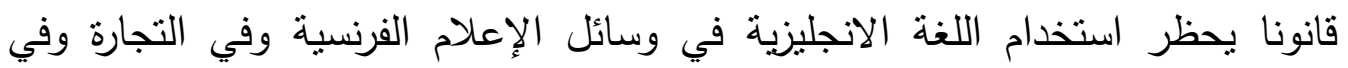

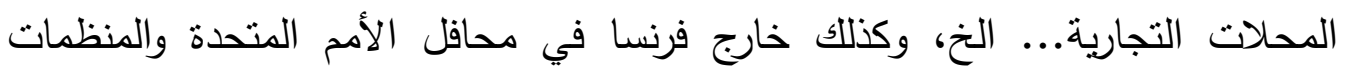

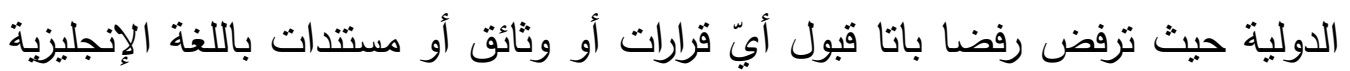

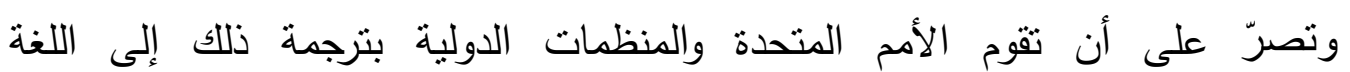
الفرنسية (36).

لذا لابد من العناية بتوطئة اللغة العربية والاهتمام بها وتطويرها والتمسك بها وهى

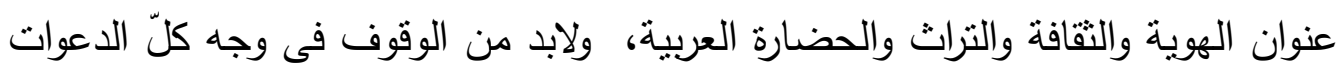

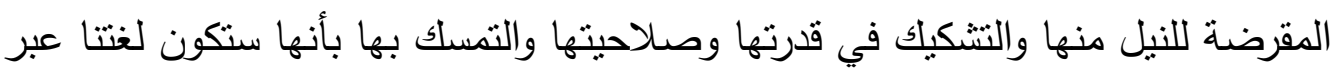

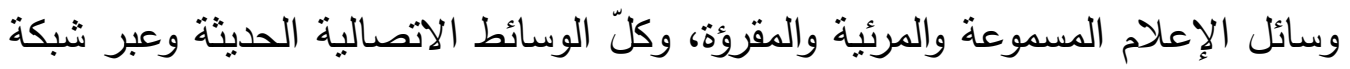

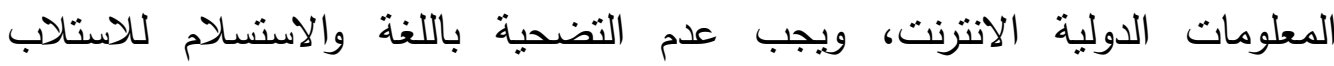

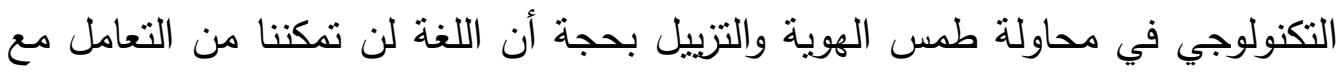

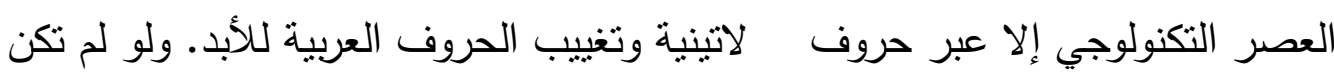


اللغة العربية فى مرحلة نضج تام لما استطاعت أن تحمل المعجزة القرآنية التي لا قرين للقرآن فى عظمة بيانه وبلاغته ولا مثيل له فى عمق معانيه وقوة حجته ودقة ألفاظه وجمال صوره.

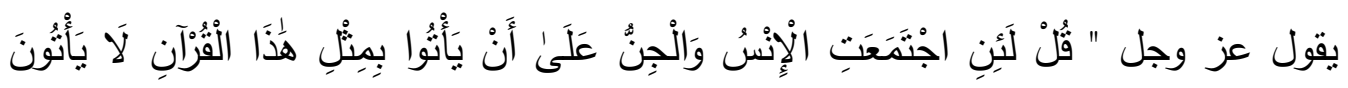

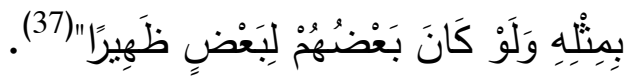
ويقول مصطفى صادق الرافعي فى هذا المضمار " إن موسيقى الكلمة العربية

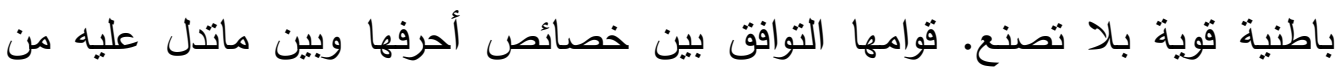

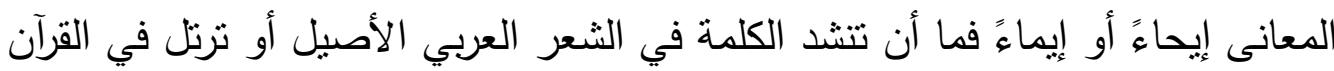

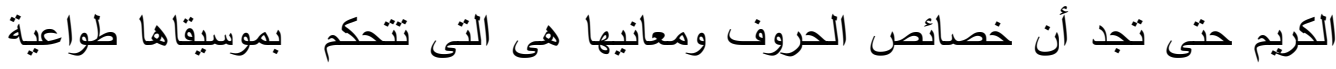

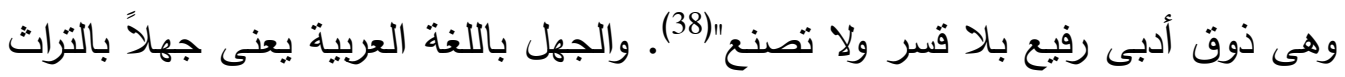

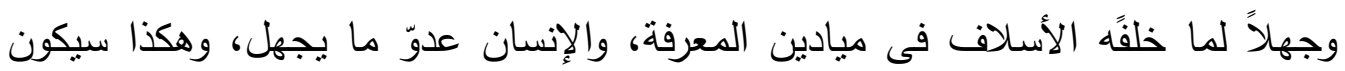

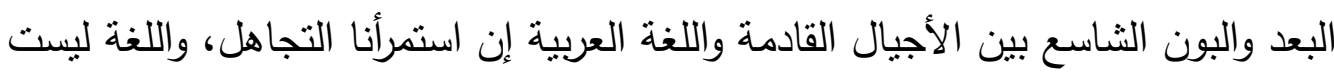

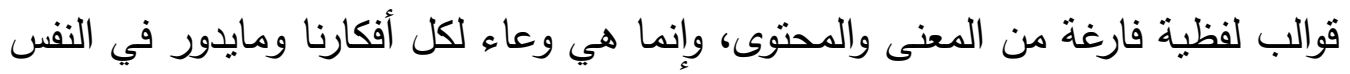

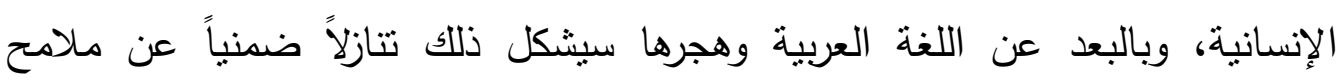

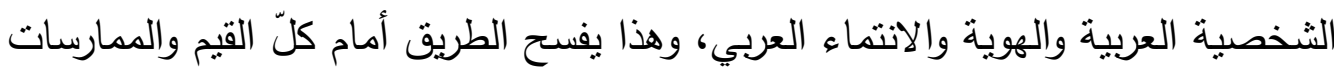
الغريبة على المجتمع بالسيطره عليه والتحكم فيه ولابد من الحذر والتوعية من مغبة ولنهاء التفريط في اللغة التى هى رمز التماسك والحضارة.

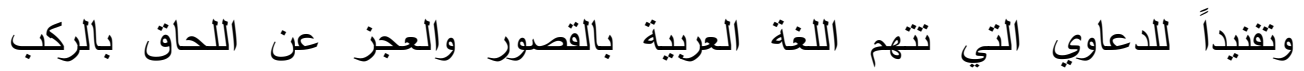
التكنولوجي الحديث والدعوة إلى إحلال الحروف اللاتينية بدلا عن الأحرف العربية.

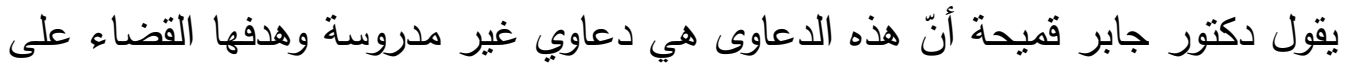

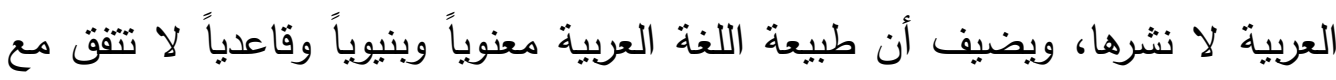

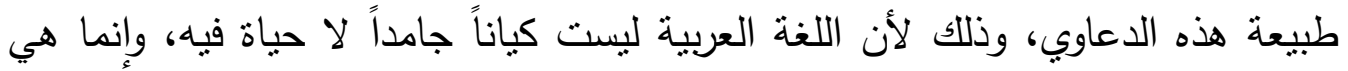

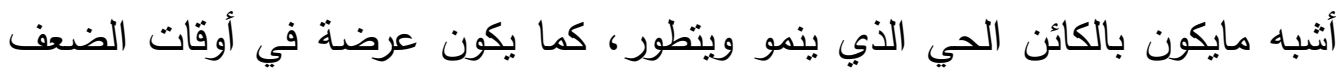


والانكسار للوهن والمرض، وقد يصاب بالثيخوخة وقد يدخل في طور الاحتضار، أو حتى الموت ولكنها في كل الأحوال: سرائها وضرائها ومنشطها ومكرهها لم تفقد هويتها، ولم تذو شخصيتها ويرجع ذلك لسبيين: أولاً: ارتباطها الوثيق بالقرآن الكريم، فهي وعاؤه العظيم، وهي أداؤه التعبيري الدعجز،

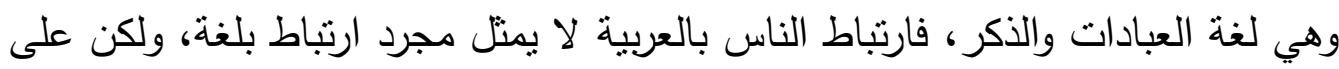

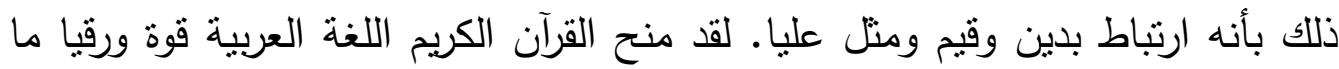
كانت لتصل إليه لولا القرآن الكريم، بما وهبها الله من المعانى الفياضة، والئ الألفاظ المتطوّرة

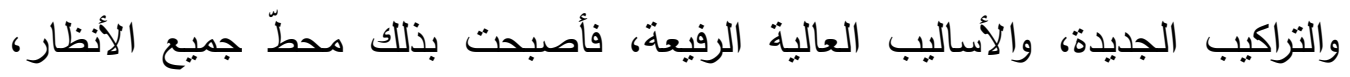

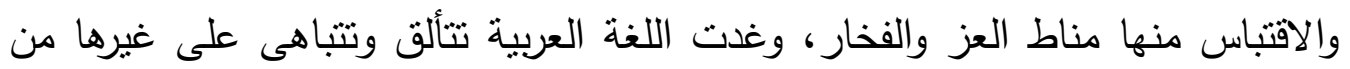
اللغات بما حازت عليه من محاسن الجمال وأنواع الكمال.

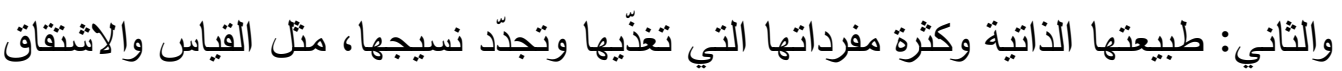
والنحت والاقتراض والالتصاق والمجاز، ممّا ينفي عنها تهمة التحجّر والعجز وضيق المدى. ثانياً: وسائل الإعلام لها أثند الأثر في رفع اللغة العربية، أو تخريبها والإساءة إليها(39).

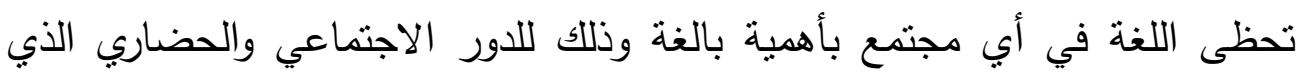

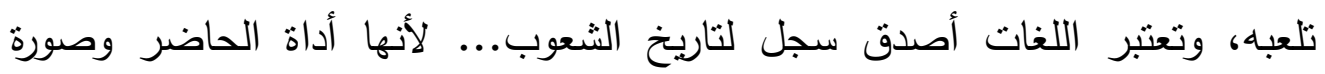

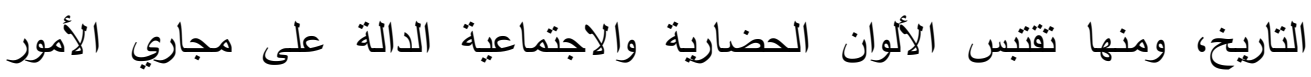

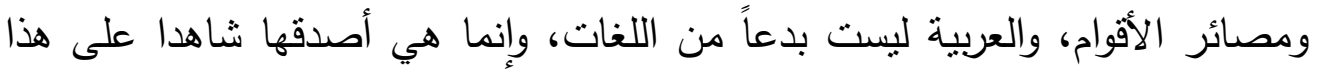

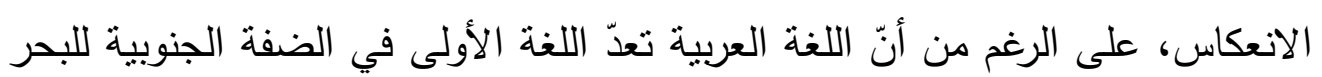

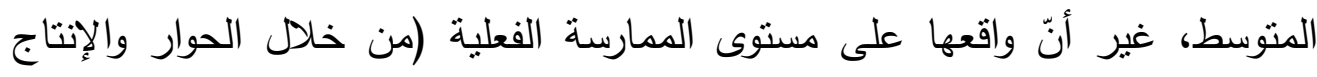

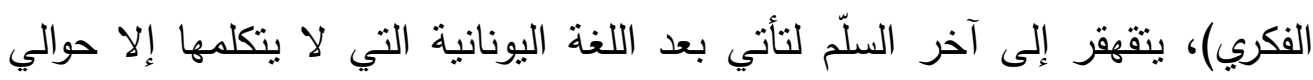

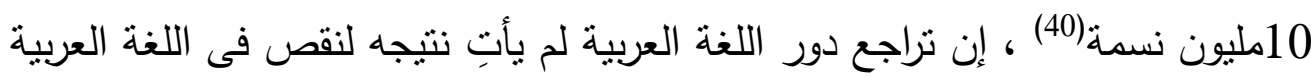

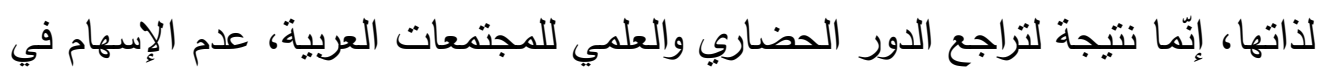


الإنتاج المعرفي والعلمي والفكري العالمي أدّي لتراجع دور اللغة العربية بين نظيراتها،

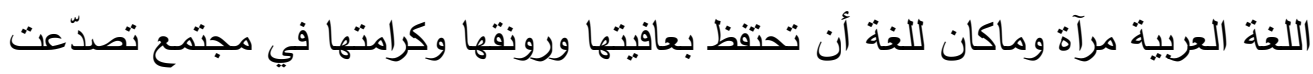

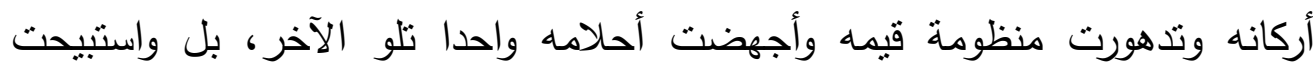

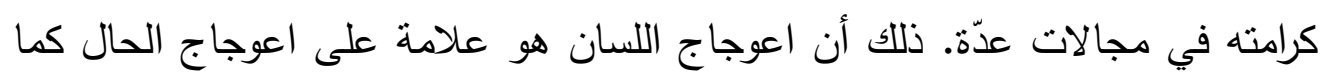

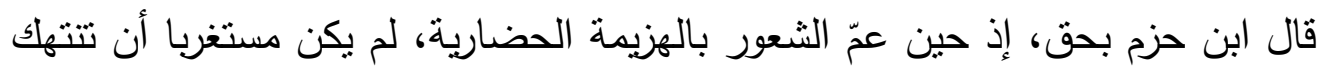

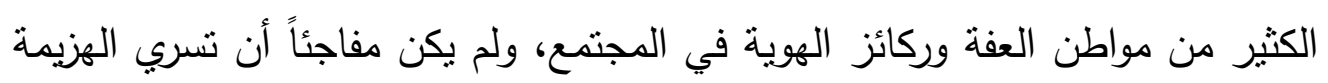
في أوصال اللغة المستخدمة، فيهجرها بعضهم، وتتكسر على ألسنة آخرين، وتهان في مختلف منابر التعبير (41). إن اللغة هى مفتاح كل القيم والموروث الثقافي والفكري والتمسك العقائدي، فبها يكون الحفاظ على الهوية. ومن هنا برزت أهمية تتمية الإحساس القومي بضرورة اللغة الفئة العربية

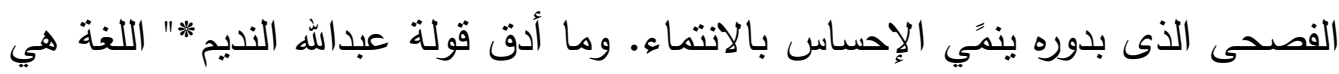

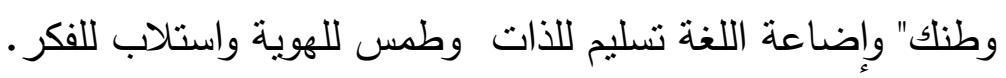

الخاتمة:

اللغة كانت ومازالت أهمّ وسيلة اتصال نعبّر بها عن أفكارنا ومعارفنا وثقافتنا

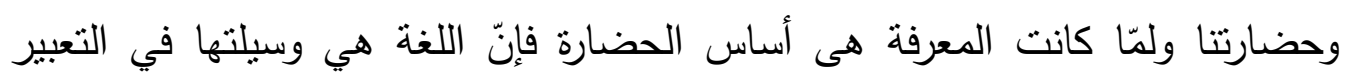

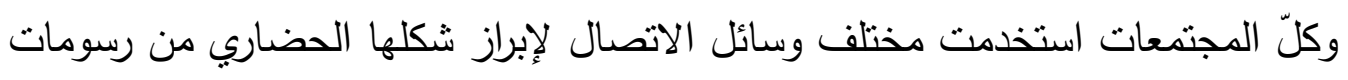

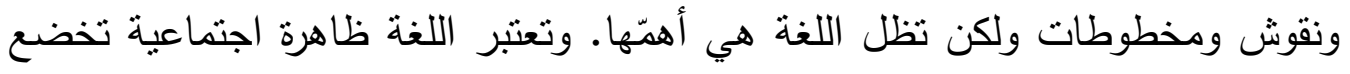

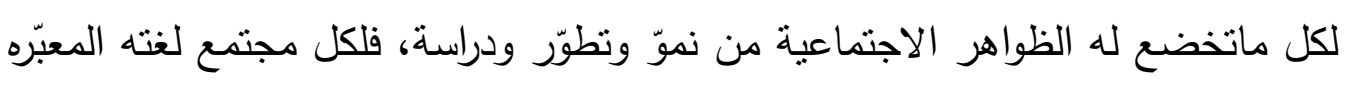

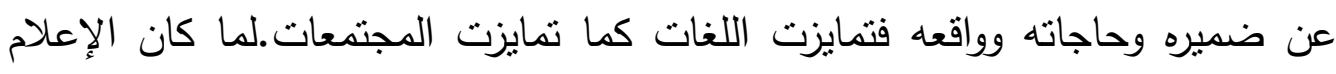

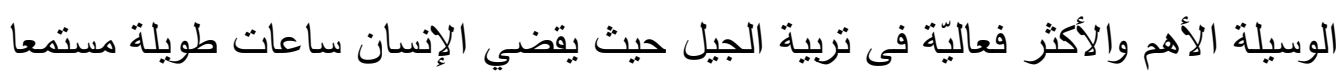

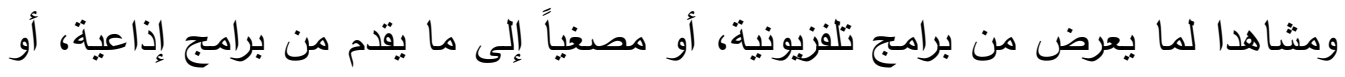

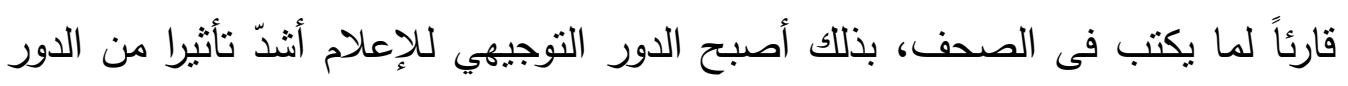

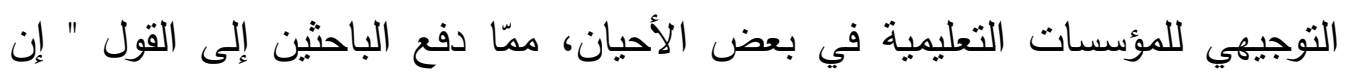


الإعلام هو المنهج التربوي الأول والمدرسة هي المنهج التربوي الثاني " وإذا كان للإعلام

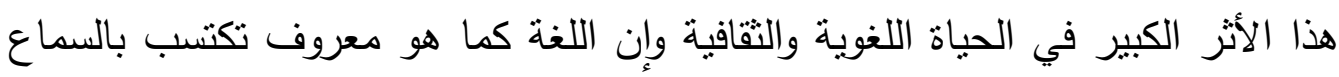

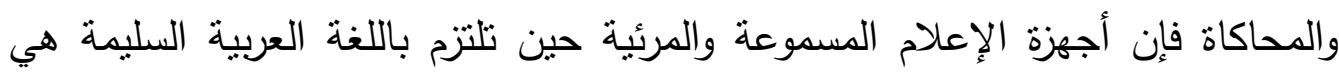

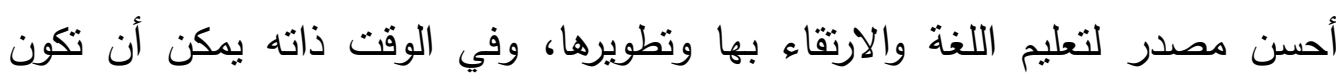

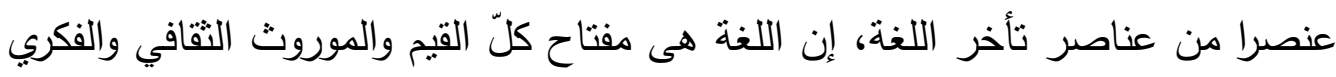

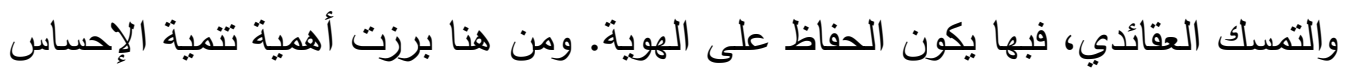

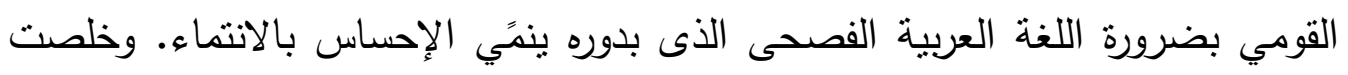
الدراسة إلى عدد من النتائج أهمها: أهم النتائج التي توصلت إليها الدراسة:

1-وسائل الإعلام تلعب دوراً كبيراً وفاعلاً فى تراجع استخدام اللغة العربية. 2- وسائل الإعلام لا تعي دور اللغة في عملية الفكر وفى الإبداع وفى مكانة الدول دورل بين الأمم. 3- اللغة العربية قادرة على تبليغ الرسالة الإعلامية إلى الجمهور فهي لغة تقوم على نسق الفن الإعلامي الحديث.

4- وسائل الإعلام لها أنثد الأثر في رفع اللغة العربية، أو تخريبها والإساة إليها.

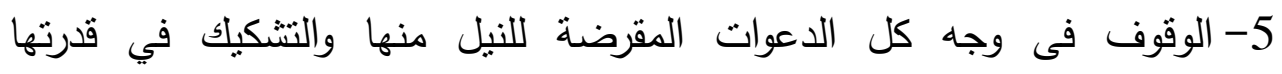

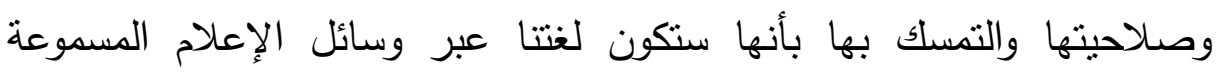

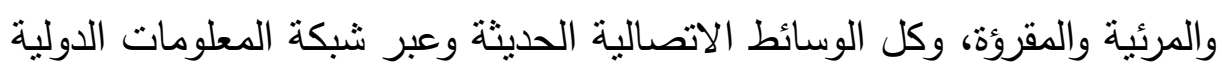

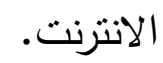

6- العلاقة بين الإعلام واللغة علاقة متلازمة، فالإعلام دون لغة رصينة ومرنة

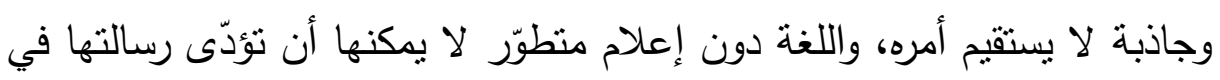
الانتشار وتعميم الذوق الراقي. 
7- عدم التضحية باللغة والاستسلام للاستلاب التكنولوجي في محاولة طمس الهوية

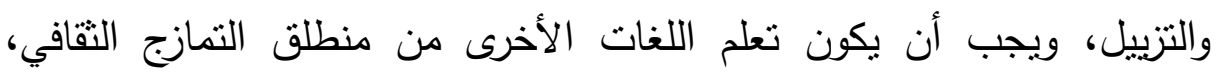

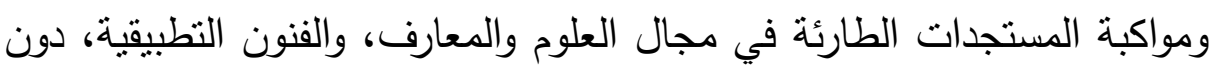
الإقلال من مكانة اللغة العربية الفصحي. 8- اللغة هى الأداة المثلى لغزو آفاق العالم الفسيحة الرحبة لتحقيق السيطرة الكاملة

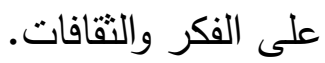

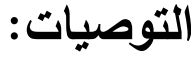

1- العناية بتوطئة اللغة العربية والاهتمام بها وتطويرها والتمسك بها وهى عنوان الهوية والثقافة والتزاث والحضارة العربية. 2- تخصيص قناة خاصة لتعليم اللغة العربية الفصحي عن بعد وتعريف الأجيال بكنوز اللغة من خلال المناشط الفنية المختلفة وإثراء هذه القناة بالقوالب الفنية

$$
\text { الثيّقة. }
$$

3- الاستفادة من وسائل الاتصال المختلفة في خلق ذائقة فنية لدى النشء من خلا تقديم برامج جاذبة باللغة العربية الفصحي تتمي لديهم الإحساس بكنوز اللغة

$$
\text { وقيمتها. }
$$

4-سن قوانين للحدّ من استعمال اللغة العامية في وسائل الإعلام بمختلف أثكالها المسموعة منها والمرئية والمقروءة. 


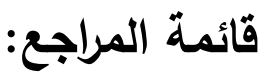

محمد عمارة،العربية وتحديات التكنولوجيا، على الرابط النالي:

http://www.alarab.net/Article/502281

(2) صالح بن حمد العساف، الدذخل إلى البحث في العلوم السلوكية، الرياض، مكتبة

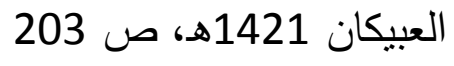

(3) محمد عدالغني هال، مهارات الاتصال باللغة العربية، ط3، القاهرة، مركز تطوير

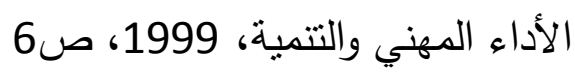

http://ar.wikipedia.org/wiki/\%D9\%81\%D9\%83\%D8\%B1 (4)

(5) أحمد بدر، الاتصال بالجماهير بين الإعلام والتطويع والتنمية، القاهرة، دار قباء

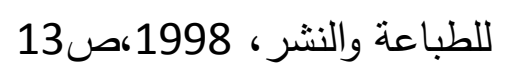

(6) ملفين ل.ديفلير، ساندرا بول، روكيش، نظريات وسائل الإعلام، ترجمة كمال

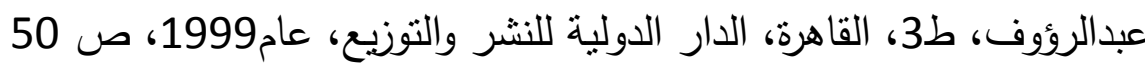

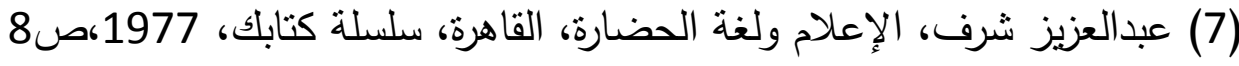

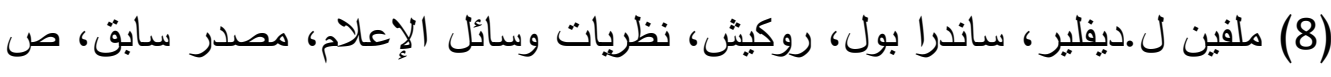
$325-324$

(9) حسين فوزى النجار، الإعلام المعاصر، دار المعارف، سلسلة اقراء، 1984، ص

(10) المرجع السابق ص 41 (11) (11)

(11) ملفين ل.ديفلير ، ساندرا بول، روكيش، نظريات وسائل الإعلام، مصدر سابق،

انظر صفحة 330-331-332

(12) عبدالعزيز شرف، الإعلام ولغة الحضارة، مصدر سابق ص 10

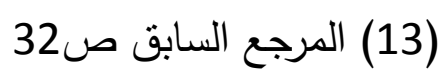

(14) حسين فوزى النجار، الإعلام المعاصر ، مصدر سابق ص41. 
(15) شون ماكبرايد، أصوات متعددة وعالم واحد، الجزائر،الثركة الوطنية للنشروالتوزيع

$$
\text { "بدون تاريخ" ص118 }
$$

(16) عبد العزيز شرف، الإعلام ولغة الحضارة، مصدر سابق، أنظر ص 35-36 (17) شون ماكبرايد، أصوات متعددة وعالم واحد، مصدر سابق ص 118 (18) المرجع السابق، ص119 (119)

(19) ملفين ل.ديفلير، ساندرا بول، روكيش، نظريات وسائل الإعلام، مصدر سابق، انظر صفحة 339-340

(20) شون ماكبرايد، أصوات متعددة وعالم واحد، مصدر سابق ص 118 (21) عبد العزيز شرف، الإعلام ولغة الحضارة، مصدر سابق، ص22 (22) حسين فوزى النجار ، الإعلام المعاصر ، مصدر سابق ص41. (23) أحمد هوبدي، عن اللغة والفكر والذات الحضاربة، على الرابط التالي: http://digital.ahram.org.eg/Community.aspx?Serial=1496745 (24) سلطان بلغيث، وسائل الإعلام واللغة العربية الواقع والمأمول، على الرابط التالي: http://www.diwanalarab.com/spip.php?article4568

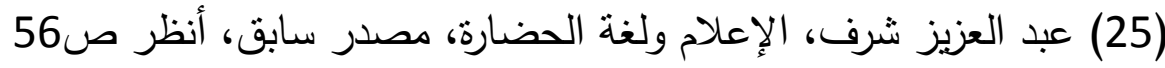
75 (26) المرجع السابق صن (26) (27) شون ماكبرايد، أصوات متعددة وعالم واحد، مصدر سابق ص343

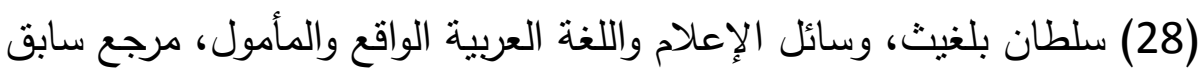

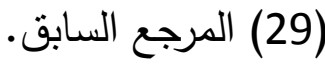
(30) جان جبران كرم، التلفزبون والاطفال، بيروت، دار الجيل، ط1، 1988، ص59 (31) سلطان بلغيث، وسائل الإعلام واللغة العربية الواقع والمأمؤل، مرجع سابق.

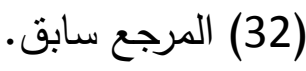
(33) زهير مشارقة، مجلة مجمع اللغة العربية بدمشق،المجلد الرابع والسبعون الجزء الثالث، انظر ص477 


$$
\text { (35) أحمد هويدى، مرجع سابق. }
$$

(35) مها قنوت، اللغة العربية والإعلام واقعها وآفاق تطورها، مجلة مجمع اللغة العربية

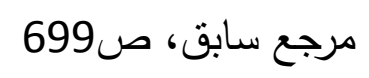

(36) فوزية العشماوي،الحوار بين الحضارات والخصوصيات النقافية، مجلة العربي،

$$
\text { على الرابط التالي: }
$$

http://www.arabphilosophers.com/Arabic/adiscourse/aeast-west/

$$
\text { (37) سورة الإسراء، الآية } 88 \text { (38) (38) }
$$

(38) تركى صقر، اللغة العربية والإعلام الدقروء، مجلة مجمع اللغة العربية، مرجع

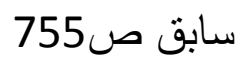

(39) عبدالرحمن هاشم، أنز وسائل الإعلام في اللغة العربية، قراءة في كتاب الدكتور

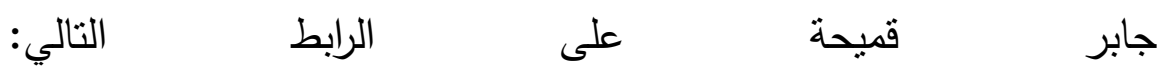

http://www.odabasham.net/show.php?sid=34467 (40) سلطان بلغيث، وسائل الإعلام واللغة العربية الواقع والمأمول. مرجع سابق.

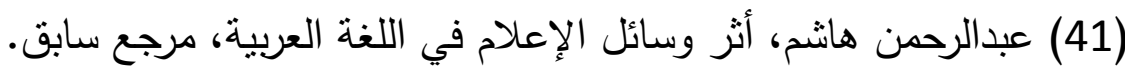

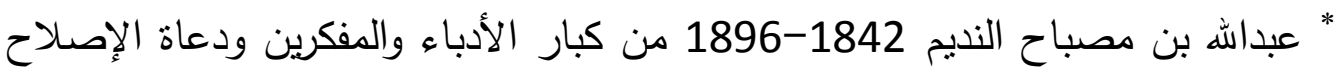
في مصر ، توفي في الاستانة. 